577.82

B 79 

$\vdots$ 
ANATOMICAL, PHYLOGENETICAL AND CLINICAL STUDIES ON THE CENTRAL NERVOUS SYSTEM 

THE JOHNS HOPKINS UNIVERSITY, SCHOOL OF MEDICINE, LECTURES ON THE HERTER FOUNDATION, SEVENTEENTH COURSE, 1926

\title{
Anatomical, Phylogenetical AND Clinical Studies ON THE Central Nervous System
}

\author{
BY \\ B. BROUWER \\ Professor of Clinical Neurology \\ University of Amsterdam
}

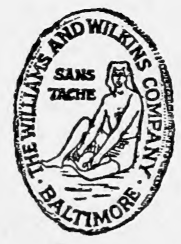

PUBLISHED FOR

THE JOHNS HOPKINS UNIVERSITY

BY

THE WILLIAMS \& WILKINS COMPANY

BALTIMORE 
Copyright 1927

The Williams \& Wilkins Company

\author{
Made in United States of America
}

Published June, 1927

Composed and Printed at the WAVERLY PRESS

FOR

The Williams \& Wilkins Company

BaLtimore, MD., U. S. A. 


\section{THE HERTER LECTURES}

In November, 1902, Dr. and Mrs. Christian A. Herter, of New York, gave to the Medical School of The Johns Hopkins University the sum of $\$ 25,000$ "for the formation of a memorial lectureship designed to promote a more intimate knowledge of the researches of foreign investigators in the realm of medical science." According to the terms of the gift, some eminent worker in Physiology or Pathology is to be asked each year to deliver a lecture at the Johns Hopkins University upon a subject with which he has been identified.

The selection of the lecturer is made by a committee representing the department of pathology, physiological chemistry, and clinical medicine of The Johns Hopkins University, and if "in the judgment of the committee it should ultimately appear desirable to open the proposed lectureship to leaders in medical research in this country there should be no bar in so doing."

\section{PUBLISHER'S ANNOUNCEMENT}

The earlier Herter Lectures, 1904 to 1923 inclusive, have appeared in The Bulletin of the Johns Hopkins Hospital.

The publishers plan to issue the lectures in book form. Announcement of titles will be made as each book is issued from the press. 



\section{PREFACE}

It was to me a great honour to be invited to deliver the Herter Lectures. I am very grateful for the splendid reception, given me by the Medical Faculty at Baltimore, April 1926. It is not necessary to thank each of my colleagues individually, because Johns Hopkins University is a real unit.

As a representative of Dutch neurology I have given my lectures, based on the anatomy and the physiology of the nervous system. Many of us in Holland work along this line.

I know that not a few of my explanations in my lectures were hypothetical and that many facts might be differently interpreted. But in preparing these Herter lectures I felt that it was not wise to limit myself to bring facts, found by my research work. My American colleagues did not ask me to come to Baltimore to hear only some objective facts. They desired also to get an impression of my personality. A personality is always dualistic, good and bad. This psychological fact is not always clear, but is always true. My ideas may be right or wrong, in any case they are part of my personality, for I believe in them.

University of Amsterdam

B. Brouwer. 



\section{CONTENTS}

\section{LECTURE I}

The Projection of the Retina in the Brain......... 3

LECTURE II

Pathology of Sensibility..................... 27

\section{LECTURE III}

The Significance of Phylogenetic Studies for the NeuROLOGIST . . ................... 45

\section{9}


(4) 
THE PROJECTION OF THE RETINA IN THE BRAIN

FIRST HERTER LECTURE 


\section{THE PROJECTION OF THE RETINA IN THE BRAIN}

The subject of my first Herter lecture is the projection of the retina in the brain. Several of your scientific workers in America have given much thought to this problem. I refer, for example, to the studies of Adolf Meyer, Cushing and G. E. de Schweinitz. I like very much to speak on this subject, because this problem has attracted me very much for several years. There is however one difficulty. I must give my lecture in a language, which is not mine and which, I fear, is also not yours. I have therefore brought a number of plates and lanternslides with me. They speak an international language and hence I hope you can understand me.

To introduce you to the problem I have to remind you that the experiences of the Great War have renewed our interest in the cerebral organization of the optic pathways. We have only to recall the careful investigations of Gordon Holmes and Lister in England, of Pierre Marie and Chatelin in France and of Axenfeld and others in Germany.

The optic stimuli are caught by the retina, thus reaching the layer of the ganglion cells. These cells send their fibres into the brain, forming in the beginning the optic nerves. These nerves, in lower animals, wholly cross. This is so in fishes, amphibians, reptiles and in birds. It is also the case in some groups of mammals. In these classes of vertebrates, however, it is usually different. In rabbits, for instance, some of the optic fibres do not cross, but remain on the same side of the brain. In monkeys and also in men, as you know, the number of non-crossing fibres is much larger. Centuries ago Newton emphasised the fact that the optic nerves in men only partially cross in the chiasma. This was a theory he had deduced in his studyroom. His 
opinion was contested by several anatomists and much work had to be done before the correctness of Newton's theory was proved. This once more demonstrates that a good theory often anticipates the facts. It depends only on the nature of the theory or, perhaps more correctly, on the quality of the brain, from which the theory issues.

What is the reason why the optic nerves in higher animals, and in men, only partly cross? This depends on the position of the eyes in the head. The more frontal they are the more non-crossing fibres are present. Cats and dogs, for example, belong to the same class in the scale of evolution. In dogs the eyes stand more laterally than in cats. Experimental-anatomical study has proved that the number of non-crossing fibres in cats is larger than in dogs.

There is still another difference in the ascending scale. I mean the development of the macula. We all know that man has a very finely organized macula. It is by this spot in the retina we can see very distinctly. A similar spot is also present in monkeys but not in rabbits and is absent in by far the largest number of vertebrates. It is also found in some animals whose sight is highly developed, for example, in many birds.

The optic fibres terminate in two primary optic stations in the brain, the external geniculate body and the corpus quadrigeminum anticum. It is often asserted that there is still a third primary station, the pulvinar. Later on I shall return to this point.

Fibres proceeding to the geniculate body conduct the stimuli by which conscious sight is made possible. They are spread throughout the geniculate body, where the second optic neuron begins. Its cells send their fibres by a long tract to the cortical optic centre, lying in the occipital lobe. The other optic fibres, proceeding to the midbrain, conduct stimuli, which may cause reflex movements of the eye muscles and of the pupils.

For many years there have been two lines of thought as 
to how the optic fibres are spread throughout the central nervous system. The chief representatives in this field are two celebrated workers, S. E. Henschen and C. von Monakow.

Henschen holds the localizations theory. In his opinion every spot of the retina has a sharp localization in the geniculate body, in the central optic radiation, as well as in the cortex. Also in his review of 1924 he holds a mathematical projection of the retina in the calcarine cortex. The upper half of the retina always lies dorsal in the optic pathways, the lower half ventral. The significance of this conception for clinical purposes is evident. When a tumour destroys the whole cortical centre on the right side, we get a left-side hemianopsia. When a tumour only destroys the dorsal half, we get the symptom of hemianopsia inferior. Inferior because the light stimuli, which are caught by the dorsal half of the retina, come from the inferior half of the field of vision. Pathological processes in the ventral part of the calcarine cortex must cause hemianopsia in the dorsal half of the field of vision.

In Henschen's opinion the macula forms no exception. It must be localized like an isle in the different pathways and also in the cortex. Views on the representation of the macula in the calcarine cortex have varied in his papers. Lately Henschen accepts the opinion, that the macula must be projected near the occipital pole.

von Monakow and his school do not believe, that the different parts of the retina can be definitely localized in the brain. The idea of a sharp localization does not appeal to them. Above all von Monakow denies that the macula has a circumscribed localization in the brain. In his opinion an isolated representation of the macula in the central parts of the brain is anatomically impossible. The high physiological significance of the macula led von Monakow to put forward the theory that the impulses from this part of the retina are spread over the whole external geniculate body, 
where they may be associated with impulses from other parts of the retina. In von Monakow's view the fibres carrying macular impressions must also be scattered over a large part of the optic radiations and of the occipital lobe. This hypothesis may explain why in lesions of the optic radiations and of the occipital cortex the hemianopsia frequently spares the central part of the field of vision, and why in cases of hemianopsia duplex central vision often remains intact.

Experiences in the Great War have led many occulists and neurologists to adopt Henschen's theory. His idea of an exact localization has come more and more to the front. Gunshots through the occipital part of the brain caused in many soldiers small circumscribed defects in their field of vision, just as might be expected according to Henschen's conception. These war cases certainly point to a certain localization, but a post-mortem examination, however, has been rarely made by these investigators. Holmes and Lister published an anatomically confirmed case of a circumscribed defect in the field of vision. A complete microscopical examination, however, has not yet appeared.

To solve the problem of the cerebral organization of vision, an exact analysis has to be made of the conditions in the external geniculate body, in the occipital lobe and in the tracts between them. Even the best clinical observations without post-mortem examination cannot give sufficient data.

When older investigators of such a high level as Henschen and von Monakow could not come together, the younger generation will have to follow other lines of research. Pick and Herrenheiser, many years ago already, pointed out another way. They made small lesions in the retina of rabbits and cats and studied the secondary degenerations in the optic nerve, in the chiasma and in the optic tracts, with the help of the Marchi method. 
These investigators, however, did not examine the projection of the retina in the primary optic stations themselves. Recently Lubsen published a careful research on the tectum opticum of a fish (Leuciscus rutilus). In this animal Zeeman made small lesions in the retina and Lubsen studied the secondary degeneration in the primary optic neuron. Stimulated by their work, I have made a study in rabbits and in higher mammals. All the investigations in this subject have been made along with Dr. W. P. C. Zeeman, professor of Ophthalmology at the University at Amsterdam. We have examined about sixty brains of animals and studied them with the help of the Marchi method microscopically in a complete series.

Prof. Zeeman made different kinds of lesions in the retina of rabbits, cats and monkeys. To dilate the pupil atropine was dropped into the animal's eye a day and again an hour before the operation. Ether was used during the operations on the monkeys and cats, in rabbits only cocaine was administered in the eye. The eyelids were kept open by retractors and by means of an electric lamp placed on the forehead of the operator light was thrown on and into the eye of the animal. With his right hand the surgeon inserted a cataract needle with a sickle-shaped edge, through the bulbar conjunctiva about $4 \mathrm{~mm}$. behind the temporal border of the cornea and then through the sclera into the vitreous. With his left hand he now 'placed an ophthalmoscope lens of 20 dioptries before the eye. In this way he could distinctly see the fundus and also the point of the cataract needle in the vitreous. With his right hand he brought this needle to the part of the fundus where the lesion was to be made. In operations on the macula the blunt side of the instrument was always turned towards the centre of the macula, and after injuring the quadrant desired, the incision was if necessary enlarged centrifugally. In a very few cases the instrument had to be quickly extracted owing 
to the animal making an unexpected movement. This necessitated a second prick. These operations are easily made, provided, of course, one has not to do it oneself.

After eighteen days the animal was killed. The size and exact position of the lesion was controlled by post-mortem examination. In all lesions of the macula in monkeys and in several of the peripheral retina, a microscopical examination in serial sections was made. In this way we got a good oversight of the conditions in the periphery.

The nervous system was treated by the Marchi method. A complete series was cut through the chiasma, the optic tracts and the primary optic stations. In several cases the peripheral nerve was also examined by this method. Our investigations were started in the Central Institute for Brain Research (Director Dr. C. U. Ariëns Kappers) and have been continued in the neurological and ophthalmological laboratories of the University of Amsterdam.

In rabbits a localization of the various parts of the retina up to a certain degree is already seen in the optic nerve. The fibres coming from the ganglion cells of the dorsal half of the retina are situated more dorsally in the optic nerve than those of the ventral part. The fibres issuing in the nasal part of the retina proceed medially from those of the temporal part. This localization is, however, not an absolute one in the optic nerve. One can find fibres of various quadrants mixed together. It is very difficult to show a special localization in the chiasma of the rabbits. This is easier in the optic tract. We have found that the upper quadrants of the retina send their fibres through the ventro-medial part of the optic tract and the lower quadrants through the dorso-lateral part. The turning of these quadrants takes place chiefly in the chiasma. Hence we may deduce that in the chiasma of the rabbit there is not only a partial crossing from the left side to the right and the reverse but also a crossing from dorsal to ventral and vice versa. 
Thus far this localization was not an absolute one, but a very distinct localization of the different parts of the retina in the primary optic centres was found. The cells of the upper quadrants of the retina send their fibres to the ventral part of the external geniculate body, while those of the lower quadrants terminate dorsally. Further, the nasal part of the retina is always projected laterally to the temporal half.

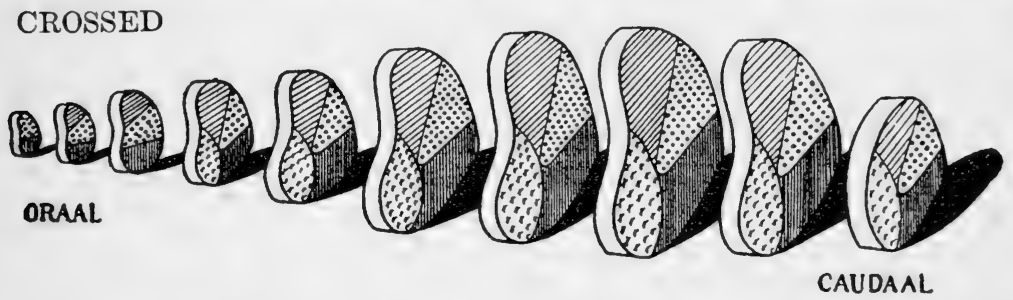

UNCROSSED

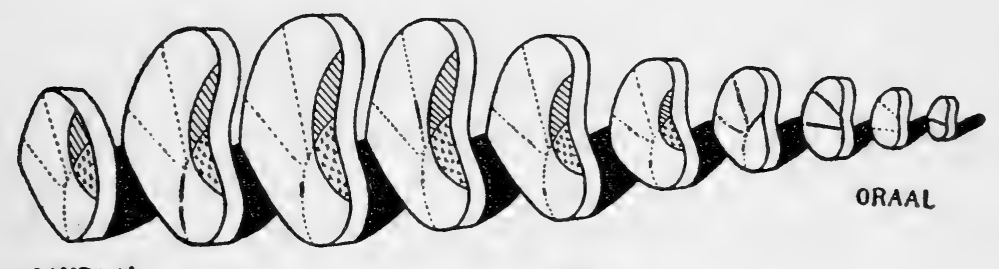

CAUDAAL

\section{Oamporal LOWER = Nasal LOWER

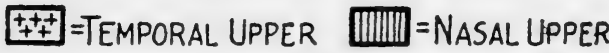

Fig. 1. Projection of the Variods Quadrants of the Retina on the Crossed and Uncrossed External Geniculate Body in Rabbits

(After Overbosch)

The uncrossed tract in rabbits is very small as I have already mentioned, because the eyes are situated so far sidewise in the head. These uncrossed fibres terminate in a pretty large, but circumscribed portion in the medial part of the geniculate body. They there mix with fibres of the crossed retina. Again the lower half lies above the upper half of the retina. In this medial portion of the external geniculate body the part of the retina by which the animal 
can look with both its eyes together, may be seen projected. Here binocular vision is made possible. The figure 1 shows this projection of the crossed and uncrossed fibres through the whole external geniculate body. They are made by Dr. Overbosch, who will shortly give a full description of the material. Regarding the uncrossed part, one point must still be mentioned. This part does not occupy the whole external geniculate body but leaves the oral part free.

In rabbits there is also a very fine projection of the retina on the corpus quadrigeminum anticum. The lower quadrants are lying oral and medial, the upper quadrants caudal and lateral. This ganglion is in rabbits of much higher significance for sight than in higher mammals and does not merely serve for lower reflex movements.

Recapitulating we conclude that the principle of localization in rabbits distinctly comes to the foreground. The position of the different quadrants of the retina is, however, unexpected.

In cats an exact localization in the external geniculate body is also found. Cats differ from rabbits. This is not surprising, seeing that the eyes in the former stand more frontal in the head, and that the form of the external geniculate body is not the same. Hence the number of non-crossing fibres is much greater than in rabbits and the binocular part of the external geniculate body has become bigger. Here also it is situated medially, as Minkowski was the first to show. We have further found that the upper quadrants of the retina lie a little more frontal than the lower. It has not been possible to determine the localization of various parts of the retina in the midbrain of cats. The secondary degenerations to this part of the brain after partial lesions of the retina were not sufficiently intense to enable us to come to a definite conclusion. Figure 2 shows Dr. Overbosch's and our results about the projection of the retina in cats. 
We shall now turn to monkeys. This animal is of the highest interest for clinical purposes, because in this respect the relations in monkeys and in men are about the same. The eyes stand quite frontal in the head, just as in man. There is a real macula, just as in man. The form of the geniculate body is about the same and this ganglion is shifted to the outside of the brain. It lies at its base, just as in man.
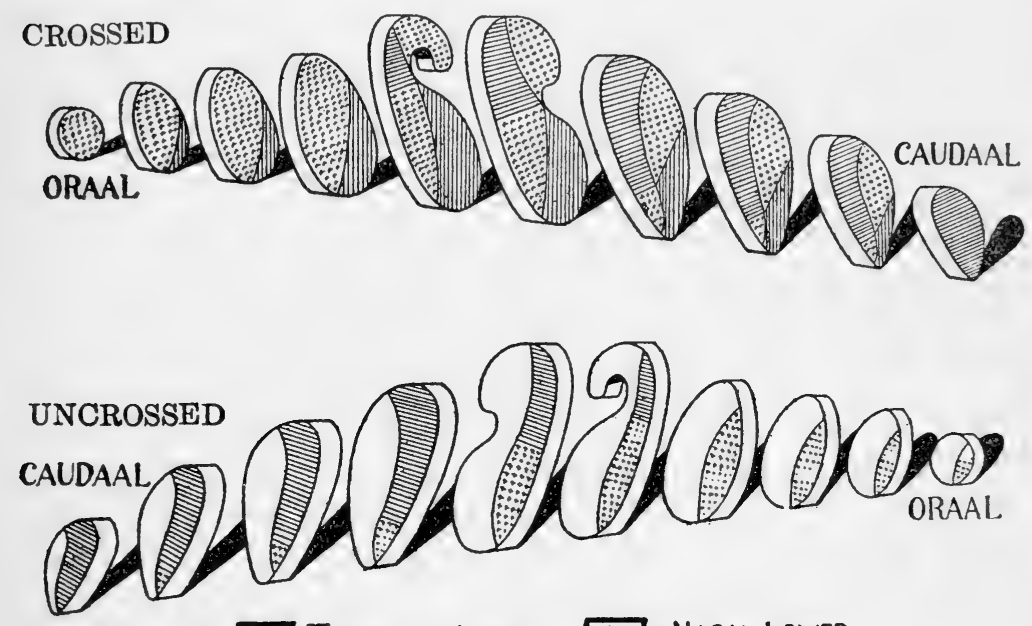

\section{TEMPORAL LOWER. NASAL LOWER.

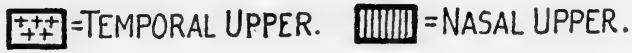

Fig. 2. Projection of the Variods Quadrants of the Retina on the Crossed and Uncrossed External Geniculate Body in Cats (After Overboseh)

The operations were always made on the left eye. In one case the left eye was totally extirpated, while in fifteen other animals partial lesions were made. These may be divided into three groups. In the first, different parts of the retina were injured without damaging the macula; in the second group the macula was involved, the remaining part of the retina being spared; while in the third, lesions were made in the macula as well as in the periphery. 
On looking over our observations of secondary degenerations in the optic nerve we find there is, to a certain degree, a localization of the peripheral quadrants of the retina. The fibres from the upper half of the retina are situated above those from the lower; further, the temporal fibres lie lateral and the nasal medial. The difficult point is the localization of the macular fibres. It is certain that the number of those fibres is large. Near the eye they are situated laterally in the optic nerve, but towards the chiasma the degenerated area has a tendency to pass more centrally into the nerve. We believe that the macular fibres separate those from the temporal upper and lower quadrants of the peripheral retina from one another. There is not a very exact localization of the macular fibres in the optic nerve, for it is certain that several of them are found between fibres from the various quadrants of the retina.

We shall now pass to the relations in the chiasma. Our experiments have shown that the fibres from the upper part of the retina generally cross dorsally in the chiasma and those from the lower half ventrally. The macular fibres cross chiefly in the middle of the chiasma. In the midule and in the most proximal sections of the chiasma it is perfectly evident that the macular fibres have a tendency to move towards its dorso-lateral part. In this way the position occupied by the macular fibres in the optic tracts, as we shall presently see, has already been determined in the chiasma.

Our observations in regarding to the position of the various parts of the retina in the chiasma of the monkey correspond to what Henschen and Wilbrand found in man. From their and our own observations we can understand why it is that tumours of the hypophysis so often cause an early defect in the superior temporal quadrants of the field of vision, since the tumour presses first on the ventral border of the chiasma and consequently damages the function of the ventral quadrants of the retina. From our invesiga- 
tions on the structure of the chiasma in monkeys the conclusion may be deduced that pressure on its dorsal surface may first cause defects in the inferior quadrants of the field of vision; some of our clinical observations point in this direction. If this is correct we should here have a means of distinguishing between tumours of the hypophysis on the one hand and suprasellar tumours or dilatation of the third ventricle on the other hand. In this line we can also use our results on localization in the optic tracts. We have found that there is certainly a localization of the fibres from the upper and lower parts of the periphery of the retina. The projection is approximately the same in both the crossed and uncrossed tracts. The fibres from the upper quadrants of the periphery lie dorsally, those from the lower ventrally; there is no overlap between these. The macular fibres are situated in the centre and gradually become larger in a lateral direction. The medioventral position of the macular fibres overlap the fibres from the dorsal and ventral parts of the peripheral retina. This localization remains the same throughout the whole length of the optic tract.

We shall now discuss the primary optic centres, but first, however, I must say something about the pulvinar. This forms a part of the optic thalamus and lies in the immediate neighbourhood of the geniculate body. It is often regarded as a third primary optic station. In rabbits it has been up to now very difficult to decide which part of the optic thalamus corresponds to the pulvinar of higher animals. After operations on the eye of rabbits, many fibres are seen to turn round the external geniculate body and then pass along the dorsal border and through the most dorsal part. of the optic thalamus. We must not infer, however, that these terminate here, as there is reason to believe that they all only pass through this region of the brain in order to reach the midbrain. In cats a pulvinar can be easily recognized, and after retinal operations a secondary degeneration can be seen in its dorsal border, smaller and less intense than 
in rabbits. We can definitely say that these fibres do not terminate there, but proceed to the anterior colliculus. We have checked this conclusion by cutting a series of sections horizontally after extirpating the left eye. In monkeys these degenerated fibres go along the medial border of the pulvinar but do not terminate there. They avoid the external geniculate body, bend caudally through the bracchium anterius and terminate in the corpus quadrigeminum anticum. Furthermore, the arguments that the pulvinar in man takes up primary optic fibres, are weak.

Hence we believe it is better not to regard the pulvinar as a primary optic centre. This does not mean, however, that this region of the brain has nothing to do with vision. The connection of the pulvinar with the gyrus angularis makes it possible that it has something to do with the movements of the eye muscles and with the higher visual functions (stereoscopic vision, the recognition of the relative and absolute distance).

When the left eye of the monkey is totally extirpated, we see an extensive degeneration in both external geniculate bodies. But this is not the same on both sides. In the crossed ganglion the degeneration is more intensive than in the non-crossed. It is very clearly seen, that in a part of the periphery of the crossed geniculate body the degeneration is more intensive than at the other side. At the ventral border of the uncrossed corpus geniculatum externum a small layer is seen which is lighter and less degenerated in our sections than on the other side.

What is the significance of this fact? The idea was forced upon us that it is in this layer that the monocular part of the field of vision is to be localized. When we compare the relations between the monocular field of vision and the binocular in rabbits, cats and monkeys, we are led to conclude as follows. In rabbits the binocular field of vision is small because the eyes stand so far lateral in the head. Hence the part of the external geniculate body reserved for 

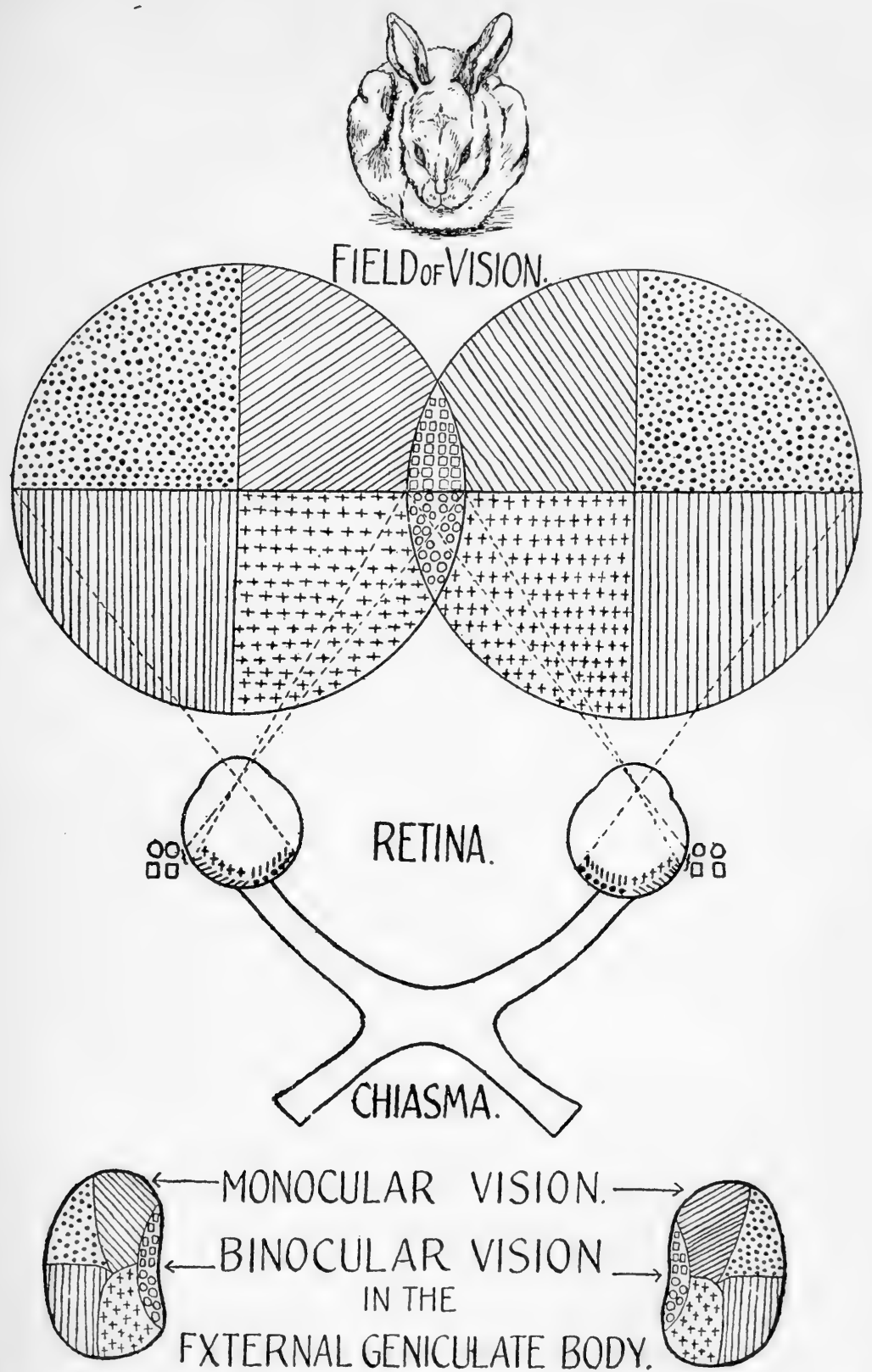

Fig. 3. Relation Between the Monocular and Binocular Fields of Vision and Their Projection on the External Geniculate Bodies IN RABBITS 
binocular vision is relatively small, the fibres of the monocular vision occupying the greatest portion. We have seen that the field of binocular vision must be localized medially in this ganglion (fig. 3). In cats the part for binocular vision becomes greater, and finally in monkeys it occupies by far the larger portion of the external geniculate body (fig. 4). Yet in monkeys, and also in man, there always remains a part of the field of vision where only one eye sees. This lies very laterally. Hence the division of the field of vision into monocular and binocular parts is of great importance. As assumed above, the former in monkeys is probably situated in the ventral layer of the crossed external geniculate body. Further investigations proved, that this view is correct. When Professor Zeeman extirpated the most nasal part of the retina, which belongs to this monocular part, in two cases, I saw degeneration only in this peripheral border of the crossed geniculate body. The largest part of this ganglion serves for binocular vision, a much smaller one for monocular vision.

The significance of the pathology of the monocular field of vision in man has been especially shown by Behr. Lutz has recently reviewed cases from the literature in which defects in the monocular field of vision were present. The anatomical aspect of this problem is, however, still unsolved. But localization of the monocular field of vision in the external geniculate body in apes may stimulate further studies in this direction. We should not be surprised if a special area is found to be reserved in the calcarine cortex also for this part of the retina.

All the secondary degenerations seen in our sections end in the corpus geniculatum externum and in the corpus quadrigeminum anticum. Our references to the anterior colliculus may be brief. In monkeys these bundles are very small, especially on the uncrossed side. The course and ending of the degenerated fibres after partial lesions in the retina differed from one another, suggesting that also in 
monkeys there is a localization of the different parts of the retina in the cortex of the corpus quadrigeminum anticum. Our material is, however, too limited to give a detailed scheme, as has been done in rabbits.

A distinction should be made between lesions in the macula and lesions in other parts of the retina. Hence we speak of macula lesions and of peripheral lesions. Our experiments show that the upper quadrants of the retina lie medial in the external geniculate body and the lower quadrants lateral. In the medial part the crossing and noncrossing fibres lie close to one another. Hence the upper nasal part of the left retina and the upper temporal quadrant of the right retina are here localized. The same is the case with the lateral parts of this ganglion, where the right lower quadrants of both retinae meet one another. The fibres from these two parts do not overlap. The difference between the specimens with lesions in the upper and in the lower halves of the retina is already apparent in the optic tracts in the neighbourhood of the ganglion; after an operation on the upper quadrants the degenerated fibres are situated medially and remain there, while after a lesion in the lower half of the retina the fibres tend to pass to the lateral side.

It has not been possible to give a more detailed localization of various parts of the different quadrants. On the contrary, we were struck by the fact that the secondary degenerations due to differently situated lesions in the same quadrants resemble each other very much. This is also the case in rabbits and in cats. From a study of our sections of the external geniculate body it is easy to determine whether the operation has been made in the upper temporal or upper nasal, in the lower temporal or lower nasal quadrant, but with the exception of the part of the retina belonging to the monocular field of vision one cannot, in this way, decide whether the lesion was made in the neighbourhood of the macula or more peripherally. 
The secondary degenerations after macula lesions were very distinct. Two points struck us here. First, that the degeneration after lesion in the macula is very large. The macular fibres are widely spread throughout the corpus geniculatum externum. They are chiefly found in those parts of the ganglion where degenerated fibres were not present after lesions of the upper and lower halves of the peripheral retina, that is, in the centre. Secondly, that in the oral part there is an overlap between the degenerated spots after injury of the macula and outside of the macula. The question now arises whether this is a real or only an apparent overlap. This matter cannot be decided with absolute certainty as we have here reached the limits of Marchi's method, but we have the feeling that there is not a real overlap. During our investigations in rabbits and cats the probability of a sharp localization always forced itself on us. This is also the case in monkeys and especially also in macula-lesions. When Professor Zeeman extirpates only the upper part of the macula, a large degeneration is seen in the geniculate body, but it shows a clear tendency to remain medially. But when he operates on the lower half of the macula the degeneration always tends to go laterally. Hence the upper part of the macula lies in the immediate neighbourhood of the upper part of the periphery. It is only in the more oral sections of the external geniculate body that this sharp localization is not found. We must not forget, however, that a large part of the optic tract passes through the oral part of the ganglion, and we believe that many of these fibres only penetrate this portion of the ganglion on their way to more central parts.

Hence we arrive at the conception, given in figure 5 . In each geniculate body there is a small part for monocular vision. This is represented at the ventral border of the periphery. The greatest portion serves for binocular vision. There is a sharp localization, the upper half of the retina lying medial, the lower half lateral. The macula has a 


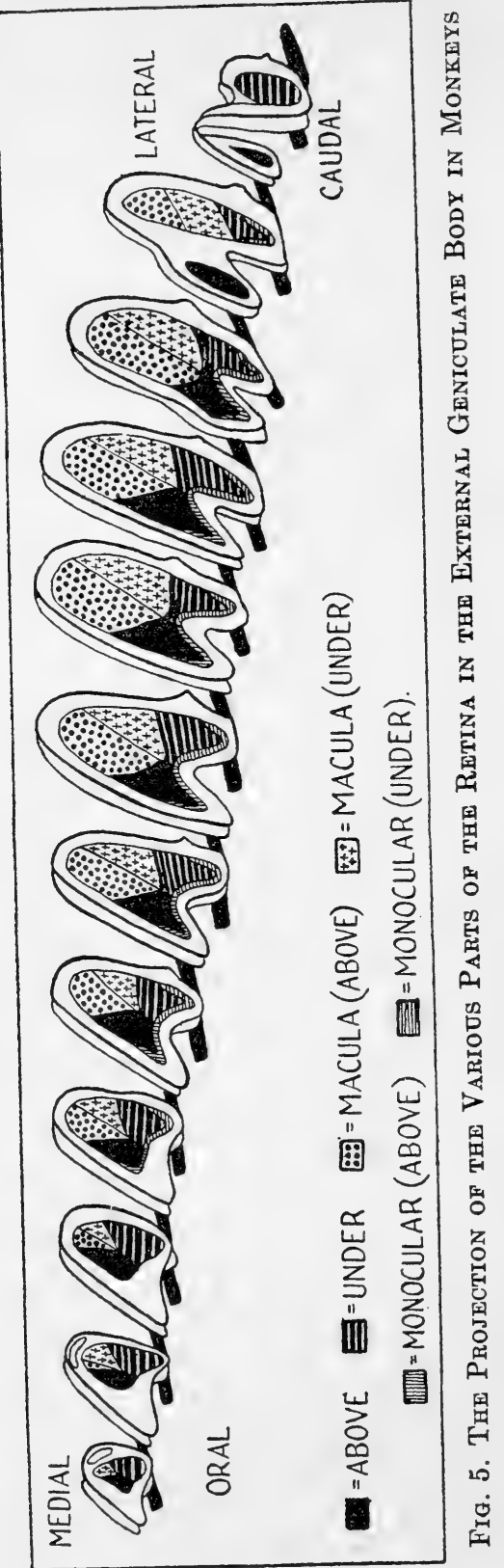


pretty large projection between them, but it is a localised one. The upper quadrant of the macula borders on the upper part of the peripheral retina and the lower part of the macula on the lower periphery. Further we believe that the horizontal meridian of the retina remains vertical, but somewhat oblique, in the corpus geniculatum externum.

You may now ask me, what is your opinion about the more central localization in the brain? I am at present engaged in my laboratory with this side of the problem and hence cannot give sufficient data. I am convinced, however, that the various opinions, generally held at this moment, cannot be correct. Because the results of our investigations enable us to conclude, that in monkeysand also in men-two parts have to be distinguished in the optic cortical centres, one for monocular and one for binocular vision. As regards the projection of the retina for binocular vision the idea of an exact localization must give the lead. But we are sure that the macula cannot be projected on a small isle of the calcarine. This projection must be a localised one, but it must be a large one. We have seen that the macular fibres are very widely distributed in the external geniculate body, but that a localization exists cannot be denied. On more careful examination we find a difference between macula and non-macula lesions. In the former the distance between the degenerated fibres is greater than in the latter. Hence they may touch more cells there than the fibrès of the periphery. In many respects our results resemble those of Rönne in man. He studied the atrophy of the cells of the external geniculate body in cases where the macular bundle was degenerated as a result of chronic intoxication; he found that in man the macula is projected on the dorsal part of the ganglion. Rönne concludes that his findings prove the connectness of Henschen's hypothesis. His diagrams, however, show that the distribution of fibres in the external geniculate body is wide.

As mentioned already above, views on the representation 
of the macula in the calcarine cortex have varied; lately it has been generally assumed that its position is in the occipital pole. In $1917 \mathrm{I}$ advanced arguments showing that it was impossible to accept the idea that the macula is localised exclusively here; in a case of hemianopia duplex caused by a lesion in both occipital lobes central vision was possible notwithstanding the fact that the occipital pole was severed from the central optic radiations. This case does not prove that the macular fibres do not terminate in the cortex of the occipital pole, but it proves that not all of them end here. In 1918 Gordon Holmes advanced the possibilityafter having studied many war cases - that macular vision, being very highly specialised, has a relatively much more extensive cortical distribution than peripheral vision has. Holmes's suggestion approximates to von Monakow's theory. It may be also in agreement with our observations in monkeys.

I made several lesions in the cortical optic centres of rabbits. Dr. Putnam of Boston studied in my laboratory the retrograde degenerations in the external geniculate body and has discovered several interesting results regarding the projection of the various quadrants of the retina on the occipital lobe, which he will publish soon. Such lesions have also been recently made in my laboratory in the calcarine cortex of several monkeys. In this way we shall be able to determine the projection of the different parts of the retina and also of the macula in the second optic neuron, because we now know the relations in the primary optic neuron. Both types of degenerations will here meet one another in the external geniculate body.

One point, however, needs to be emphasized. In our investigations we also took account of the third dimension, as you have seen in my drawings. Up to now workers have always spoken of a localization dorsal and ventral, lateral and medial. It will also be necessary to determine a localization oral-caudal. Our feeling is, that this localiza- 
tion in the third dimension will explain several clinical facts better than was formerly possible. It was not, however, my intention to tell you about my feelings on this subject, but to bring you the facts obtained through the research work of Professor Zeeman and myself.

\section{BIBLIOGRAPHY : LECTURE I}

ARIËNS KAPPERS, C. U.: Vergleichende Anatomie des Nervensystems der Wirbeltiere und des Menschen. Bohn, Haarlem, 1921.

Brouwer, B.: Ưber die Sehstrahlung des Menschen. Monatschrift für Psychiatrie und Neurologie, Band 41, 1917.

Brouwer, B.: Experimentell-anatomische Untersuchungen über die Projektion der Retina auf die primären Opticuszentren. Schweizer Archiv für Neurologie und Psychiatrie, Band XIII, 1923.

Brouwer, B., AND ZEeman, W. P. C.: Experimental anatomical investigations concerning the projection of the retina on the primary optic centres in apes. Journal of Neurology and Psychopathology, 1925.

Brouter, B., and Zeeman, W. P. C.: The projection of the retina in the primary optic neuron in monkeys. Brain, Vol. 49, 1926.

Cushing, H.: Distortions of the visual fields in cases of brain tumor. Transactions of the American Neurological Society, 1921.

Holmes, Gordon, and Lister, W. T.: Disturbances of vision from cerebral lesions, with special reference to the cortical representation of the macula. Brain, Vol. XXXIX, 1916.

Holmes, Gondon: Disturbances of vision by cerebral lesions. British Journal of Ophthalmology, 1918.

Henschen, S. E.: Revue critique de la doctrine sur le centre cortical de la vision. XIII ${ }^{\circ}$ Congres international de Médecine, Paris, 1900.

Henschen, S. E.: On the value of the discovery of the visual centre. Scandinavian Scientific Review, Vol. III, 1924.

MEYer, A.: The connections of the occipital lobes and the present status of the cerebral visual affections. Transactions Association American Physicians, 1907.

Mrnkowski, M.: Étude sur les connexions anatomiques des circonvolutions rolandiques, pariétales et frontales. Archives Suisses de Neurologie et de Psychiatrie, 1924.

Mrnkowskr, M.: Sur les conditions anatomiques de la vision binoculaire dans les voies optiques centrales. l'Encéphale, 1922.

von Monakow, C.: Die Lokalisation im Grosshirn und der Abbau der Funktion durch kortikale Herde, Bergmann, Wiesbaden, 1914.

Pfeiffer, R. A.: Myelogenetisch-anatomische Untersuchungen über den zentralen Abschnitt der Sehleitung. Monographieën aus dem Gesamtgebiete der Neurologie und Psychiatrie, Heft, 43, 1925. 
Rönne, H.: Die anatomische Projektion der Macula im Corpus geniculatum externum. Zeitschrift für die gesamte Neurologie und Psychiatrie, Band XXII, 1914.

DE Schweinitz, G. E.: The Bowman Lecture, 1923. Transactions of the Ophthalmological Society, Vol. XLIII.

Wilbrand, H., and Saenger, H.: Die Neurologie des Auges. Wiesbaden, Bergmann, 1915.

WinkLeR, C.: Lokalised atrophy in the corpus geniculatum laterale. Proceedings Royal Academy for Sciences, Amsterdam, 1912. 


\section{PATHOLOGY OF SENSIBILITY}

SECOND HERTER LECTURE 


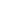




\section{PATHOLOGY OF SENSIBILITY}

Pathology of sensibility is one of the chief means used in diagnosing and localising diseases of the nervous system. Important work on this field of study has been done by Henry Head and his co-workers in England. He examined many cases of lesions of the peripheral and central nervous system, where disturbance of sensibility was the most prominent symptom. Topping his investigations was an experiment, done on himself. One of the nerves on his left arm was cut and then sewn by a surgeon. The disturbances of sensibility, caused by the operation, and their recovery were for some years carefully studied by him and his friends.

I take for granted that you know Head's work, hence I shall only refer to the principal points.

In the opinion of Head, Rivers, Sherren and others there are three chief means by which stimuli for sensibility are caught up in the periphery. The first is deep sensibility, which originates chiefly in the muscles and in the joints. By this, impulses produced by pressure and by movements are conducted to the central nervous system.

The other two systems conduct stimuli, caught in the skin and in the subcutaneous tissue. These systems are the protopathic and the epicritic. The former responds to painful cutaneous stimuli and to the extremes of heat and cold. The latter, the epicritic sensibility, serves for light touch, for discrimination of two points and for appreciation of the finer degrees of temperature.

This conception of Head and his co-workers was very revolutionary and hence this theory has been much criticised. In coöperation with one of my pupils-Dr. SchoondermarkI examined at Amsterdam many lesions of the peripheral 
nerves in man and studied their recovery. We have seen many of the facts described by Head. Our investigations however, did not convince us, that the theory of the existence of two distinct pathways for protopathic and epicritic sensibility has yet been proved. But we felt that this work is a great advance in science, especially because phylogenetical ideas have been introduced into the doctrine of clinical sensibility and that autonomic sensibility has been brought to the foreground. Protopathic sensibility namely, is the primitive form of peripheral sensibility and must be very old in phylogenesis. Epicritic sensibility is a higher and more complex form and develops later. In Head's opinion protopathic sensibility is closely connected with centripetal sympathetic fibres.

In discussing the autonomic nervous system many physiologists and neurologists consider only the centrifugal side, that is, they speak about the sympathetic nervous system in so far as it has been analysed by Langley. But in my opinion, this is too narrow. We know there are also many sympathetic fibres, for instance, in the intestines, which send impulses in the direction of the central nervous system. This is also the case in the vagus, which belongs to the parasympathetic system of Langley. We are aware that many stimuli from the lungs, the larynx etc. are sent to the brain along this nerve.

It is true, that this centripetal side of the autonomic nervous system has not been so clearly analysed as was the centrifugal by Gaskell, Langley and others. But still we know sufficient facts to work with in physiology and in clinical examination. Huber has proved that in the walls of the blood vessels there are many unmedullated sensory fibres. When stimulated by pinching the blood vessels during an operation under local anaesthesia, severe pain is often felt by the patients. Recently Leriche and Tournay in France have shown that sensory impulses may indeed be conducted by sympathetic fibres. 
All the sensory stimuli, caught in the periphery of the body, are sent to the spinal cord and to the brain. For a better understanding of the matter we shall limit ourselves to the spinal cord. The same line of thought may be followed concerning sensibility of the head, which is conveyed to the oblongata by the trigeminal nerve.

Thus the stimuli for touch, pain, temperature and the proprioceptive sensibility reach the intervertebral ganglions and then proceed through the posterior roots. Here in America Ranson found after careful investigations that there are many unmedullated fibres in the posterior roots. He believes that these conduct the protopathic sensibility of Head.

What happens when all these stimuli are brought by the posterior roots into the spinal cord? In the conception of Head and others a new grouping of the sensory impulses arises as soon as they reach the central nervous system. One group reaches the gray substance on the same side and here the first sensory neuron ends. A new neuron issues in the cells of the posterior horns. It mostly crosses and proceeds upwards in the antero-lateral part of the spinal cord. The other group avoids the gray substance and ascends in the posterior column on the same side. It ends in the nuclei of Goll and Burdach, which lie at the upper border of the spinal cord. Here it is that the second sensory neuron begins, crosses in the oblongata and ascends to the optic thalamus.

The investigations of Petrèn, Fabritius, Head, van Valkenburg and others have made us pretty well acquainted with the physiological significance of these two systems. The sensory pathways in the posterior columns of the spinal cord conduct stimuli of deep sensibility and a part of the tactile impulses. The other system comprises the stimuli for pain, heat and cold and the remaining part of tactile sensibility. Many investigators consider the sensibility of the posterior columns as a higher form. It enables us to 
recognise the shape and size of the objects and to distinguish two points applied simultaneously (discrimination). Amongst other things the function of stereognosis is rendered possible by the impulses conducted in this part of the spinal cord. The other form serves more for feeling and is more vital, while the former is more intellectual in character. Hence they are opposed to one another and are called the "gnostic" and the "vital" sensibility.

All these sensory stimuli are sent upwards to the optic thalamus, which is a centre where sensory functions are associated. From the optic thalamus they are sent to the cortex of the brain and meet there with many other stimuli of different qualities.

The way, however, in which these two systems are spread throughout the central nervous system differs greatly. The construction of the socalled gnostic sensibility is simple as compared with the other. It is composed of three wellknown neurons. The first is the tract in the posterior column, the second is the mesial fillet, the third the radiation between the optic thalamus and the cortex. This tract ends in the gyrus centralis posterior. The pathway for vital sensibility is more complex. As above mentioned, the second neuron begins immediately after the first neuron has entered the spinal cord. Several of these stimuli are conducted through the socalled spino-thalamic tract, but many of them are also led by short pathways, connecting the gray substance of different levels of the spinal cord, the oblongata and the midbrain. There is not much known about the termination of vital sensibility in the cortex, but we are sure, that these fibres have a large and diffuse projection in the cortex of the brain. A great part of the cortex cerebri may be destroyed in men and in animals without causing any defect to vital sensibility. In opposition to this, a circumscribed destruction of the sensory cortex, by gunshot wounds for example or by a tumour, may cause clear disorders of the 
functions of gnostic sensibility. Astereognosis especially is frequently seen in such cases.

Clinical and anatomical studies have given me the conviction that the same division into two pathways is present in the sensibility of the head, conducted by the trigeminal nerve. The so-called spinal root of the fifth nerve is the homologon of the gray substance of the posterior horn. Here stimuli are conducted for pain, heat and cold and a part of those for touch. The other sensory functions are led by the frontal trigeminal nucleus, which is the homologon of the nuclei of Goll and Burdach. From these centres also two different pathways proceed in the direction of the optic thalamus and of the cortex.

The fact that several investigators regarded the sensory functions of the posterior columns as a higher form of sensibility, has led me to make a study of the development of these sensory systems in the scale of evolution. In the Central Institute for Brain Research I studied sections of the spinal cord, stained after Weigert-Pal, van Gieson and with Carmine, of the following animals.

Fishes: Chimaera, Amia calva, Acipenser sturio, Rhombus maximus, Silurus glanis, Lophius boudegassa.

Amphibians: Rana, Siren lacertina.

Reptiles: Python, Lacerta, Varanus, Chamaeleon, Chelone mydas.

Birds: Ciconia alba, Spheniscus demersus, Colymbus septentrionalis, Casuaris.

Mammals: Homo, Cebus, Leontopithecus rosalia, Callitrix, Simia Satyrus, Hylobates, Cedipomidas, Felis, Canis familiaris, Heliarctos malayanus, Putorius putori, Bos taurus, Hippotragus niger, Elephas, Tragulus javanicus, Lepus, Dasyprocta, Phocaena, Sorex, Talpa, Macropus, Tamandua, Didelphys marsupialis.

The first cervical segment of these animals was measured and the relation between the size of the posterior columns and of the remaining part of the white substance was determined. For details I refer to my article formerly published. The principal results were the following. 
In the lowest classes of vertebrates, in fishes, the posterior columns are very small, hence the posterior horns lie close to one another. There are some tracts in these posterior columns, but they are only composed of reflex fibres, connecting the different levels of the spinal cord. These animals have no nuclei of Goll and Burdach and a real lemniscus medialis as in higher vertebrates is not present. The systems for vital sensibility, the spino-thalamic tracts of Edinger are found however. These tracts lead the sensory stimuli in the direction of the oblongata, the midbrain and the optic thalamus.

The spinal trigeminal root is also easily found in all sections of fishes and is even often large. Judson Herrick has shown, that in Teleosts a frontal trigeminal nucleus is not present. I studied complete serial sections of Rhombus maximus and of Lophius boudegossa but could not see a nucleus which may be homologised with the frontal trigeminal nucleus of higher animals. All the sensory stimuli which touch the head of the fishes go into the spinal root. The part of these, not immediately flowing down in reflex movements, but sent in an oral direction, is conducted by the secundary trigeminal systems, issuing in the cells of the substantia gelatinosa of the trigeminal root. The fishes therefore have only the vital form of sensibility, which we may call the palaeotype.

As soon, however, in the scale of evolution, as life on land has been possible, new demands are made on sensibility. Thus a new pathway is formed. This is the system called above the gnostic sensibility. In lower animals, for example in amphibians, reptiles and in birds, this second pathway is still small, but grows in the ascending scale and is largest in man. We called this the younger form of sensibility, the neosensibility. I refer to figure 6 in which sections of the first cervical segment of the spinal cord in various animals are photographed.

The same relation is present in the trigeminal systems. 


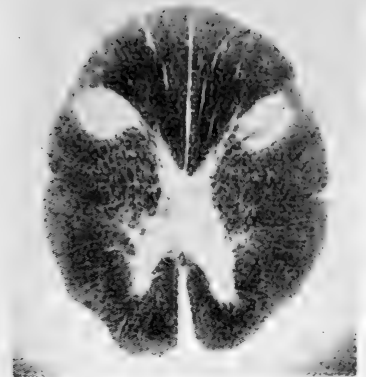

A. Homo

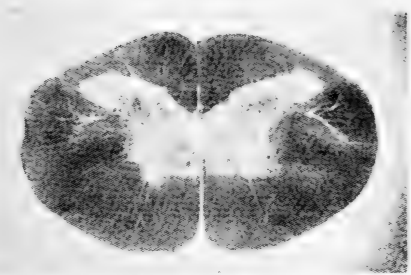

C- Cow

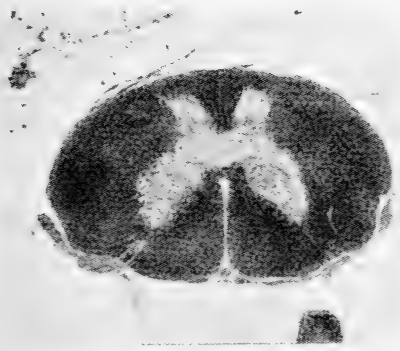

E-Stork

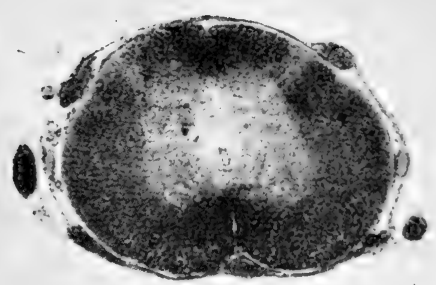

G-Frog

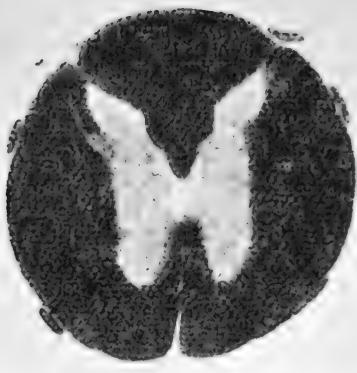

B- Monkey

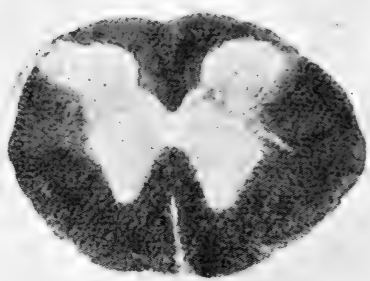

D- Opossum

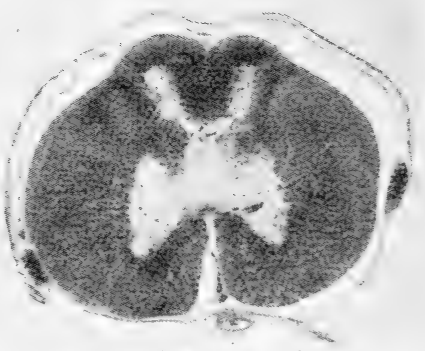

F-Serpent

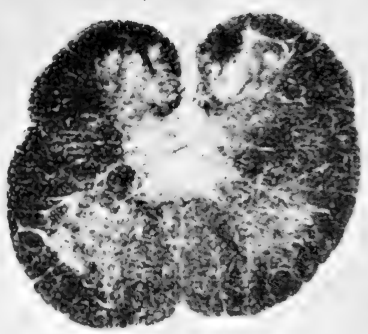

H-Fish

Fig. 6. The First Cervical Segment of the Various Classes of VERTEBRATES 


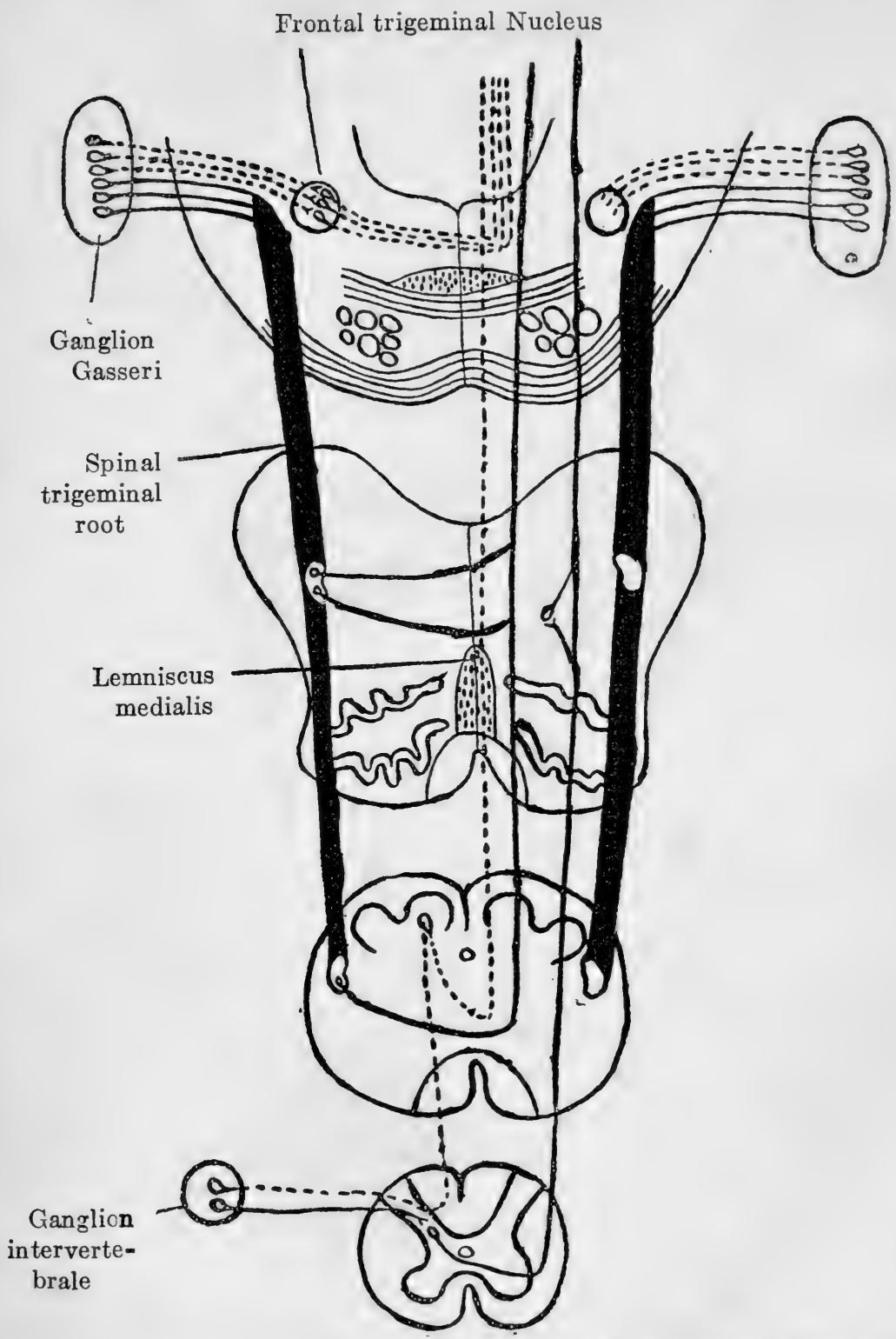

Fig. 7. Older and Newer Sensory Pathways in the Spinal Cord and in the Meddlla Oblongata

Black lines: palaeosensibility. Dotted lines: neosensibility 
A real frontal trigeminal nucleus is present in amphibians and in reptiles, in birds and in all mammals. Figure 7 gives a scheme of the relations in the fifth nerve. In the old systems (black in this diagram) the reflex stimuli and the stimuli for pain, heat and a part of touch are conducted (palaeosensibility). In the younger systems (dotted in this diagram) the chief part of touch, and the pathways for deep sensation and tactile discrimination are localised.

Investigations, made in coöperation with Dr. Zeehandelaar, showed that in the human development the same relation exists, at least in regard to the spinal cord. In the human foetus of 5 centimeters, for example, the posterior columns are still very small. They grow gradually in older foetera and in children and in this way we see that ontogenetic development runs parallel with the phylogenetic.

Looking over the results, thus far obtained, we may deduce the following points. Clinical investigations teach that a higher form of sensibility must be led by the posterior columns, the more primitive one by the lateral columns. The study in comparative anatomy shows that the oldest form of sensibility must be localised in the antero-lateral tracts, the newer form in the posterior columns. Hence it seems correct to accept the conclusion that this neosensibility corresponds with the above mentioned higher form of sensibility.

More recent investigations, however, have shown that the palaeosensibility does not remain the same during evolution. Just as is so often seen in the central nervous system the old parts develop further and are more finely organised in higher animals and in man. This is also the case in the primary fields of sensibility. The posterior horn of the spinal cord in reptiles and in birds is of a much simpler build than in man, and, the substantia gelatinosa Rolandi, for instance, is not present there. This part of the posterior horn develops in mammals and interesting investigations by Ariëns Kappers have shown that mammals with a rich development of 
peripheral autonomic systems have also a finely organised posterior horn. Hence I believe it is not correct, at the present stage of science, to speak of a higher form of sensibility which is conducted in the posterior columns and of a lower form which is conducted in the anterior part of the lateral columns.

In my opinion the chief difierence between these two forms of sensory pathways is the following. The so-called vital sensibility is closely connected with autonomic functions, and, as I mentioned already, much of it is brought to the central nervous system by non-medullated fibres. At all events it is associated in the gray substance with sympathetic centres and there causes, amongst other things, reflex movements in the sympathetic area. This form of sensibility causes feelings, which are of significance for the emotional life.

The other form of sensibility proceeds through the posterior columns and avoids the gray substance. It sends collaterals to this part of the spinal cord, but does not terminate there. The impulses, conducted in the direction of the cortex, do not originate in the autonomic nervous system and are not associated with it. They should be called non-autonomic.

Hence we reach the following conception about the organisation of sensibility in the central nervous system. The sensory stimuli are spread through the spinal cord and the brain in two separate systems. The first is the nonautonomic system. It is composed of long tracts, of simple build and enters the cortex of the brain in a circumscribed area. This organisation bears the stamp of an exact localization. In this system impulses are conducted for gnostic sensory functions, which at a high level of the brain may cause sensory observations but no sensory feelings.

The second is the vital system, closely connected with the autonomic system. It is composed of some long and of many small tracts, very complex in build, and enters the 
cortex of the brain in a diffuse way. The principle of an exact localization is not found here, on the contrary, these stimuli are diffusively spread throughout several parts of the central nervous system. In these pathways stimuli are conducted for vital sensibility, which at a high level of the brain may cause sensory feelings.

It is clear that both these forms of sensibility always work together in the cortex cerebri and that they constantly interact. It is this constant separate coöperation, that enables us to form ideas of the outer-world, in so far as this is possible by sensory stimuli.

You understand that an exact knowledge of the organisation of sensibility helps greatly to diagnose diseases of the nervous system and to localise pathological processes in the brain and spinal cord. In this connection I remind you especially of traumatic lesions, infectious diseases, tumours and sclerotic degenerations. From all these clinical pathological syndroms, I shall take tumours, because these form a part of neurology, where biological research and practical application coöperate to attain therapeutic results. From these tumours I shall select those of the spinal cord.

You know that tumours of the spinal cord may cause disorders of motility, of sensibility and of autonomic functions. The state of these disturbances depends on the level of the tumour in the spinal cord. Above all, the disturbances of sensibility enable us to localise the exact level of a tumour. The doctrine of the segmental anatomy has made this possible. All the sensory impulses enter the spinal cord by the posterior roots and we know by the investigations of Bolk, Sherrington, Kocher and others, that each root and each segment of the spinal cord belongs to a well localised and well known part of the skin. The part of the skin which is innervated by a segmental root is called a dermatom. There are several schemes indicating how these dermatoms are distributed. In Holland we always use Bolk's diagrams. 
By careful preparation Bolk followed the fibres of the various posterior roots up into the skin.

The principle of segmentation in the spinal cord is clearest in vital sensibility. In syringomyelia, for example, a disease in which a tumour, composed of gliacells, chiefly grows in the gray substance, there are amongst other things analgetic and thermo-anaesthetic areas in the skin, which may show the same form as the dermatoms.

There are also affections in which only gnostic, nonautonomic sensibility suffers. A good example of this is pernicious anaemia. A certain percentage of patients suffering from this blood disease has symptoms of affection of the central nervous system. In the early stages of the disease one may often see disturbances of deep sensibility and of finer touch in the legs, the other sensory functions being normal. This is explained by the fact, that in these cases there is only a parenchymatous degeneration of the posterior columns, without any affection of the posterior roots. In later periods of this disease the lateral columns are also suffering and other symptoms appear.

In most diseases of the spinal cord both non-autonomic and vital sensibility are affected. In tabes, for instance, all kinds of sensibility may suffer. This can easily be understood when we remember, that in tabes the posterior roots themselves are affected. In these roots all the fibres of the different sensory qualities lie close to one another and hence all suffer together by spirochaetosis.

In tumours, which press on the outside of the spinal cord, the disturbances of sensation vary greatly. To localise the exact level of the tumour we regularly use these dermatoms. When, for example, a tumour presses on the first thoracal segment, disorders of sensibility arise in such a form that the upper border of the disturbed area is the same as the lower border of the next segment which is free. So it seems to be very simple to localise tumours of the spinal cord and to send them with a correct diagnosis to the surgeon. But 
experience teaches that this is not so easy. Not unfrequently the spine is opened and no tumour is found. A neurologist, who never had such a disagreable experience, has not yet had experience enough. One of the chief causes of this is that the limits of these dermatoms are not as precisely known as they should be. The dermatoms in our diagrams are a little schematic and all these successive dermatoms partly overlap one another.

Such an overlap has been carefully determined by Sherrington, Winkler, van Ry̆nberk and others in animals. They have cut the posterior roots and examined the analgetic areas in the skin, caused by this operation. In most places of the body three posterior roots must be dissected, before an analgetic area appears. Clinical experience indicates that in man there is also an overlap between successive dermatoms. The dermatoms in the figures of Bolk are, it is true, a little too small. Still there remain many differences between the results of the experimental work on the one hand and of the clinical and anatomical work on the other hand. Many of these differences can be explained owing to the different form of the body. In a former article I showed that the form and the position of the dermatoms in man and in animals are influenced by the form of the body. The form of the neck, for example, and the relation between the size of the legs and the trunk is quite different in animals from man. Hence it is not correct to use the dermatoms of Sherrington and others, determined for animals, in our clinical work.

The diagnosing of the exact level of tumours on the spinal cord has been lately greatly helped by the discovery of Sicard and Forestier. After puncture of the cisterna magna - first done by J. B. Ayer-lipiodol is injected and a $\mathrm{X}$-ray examination of the spine is made. X-rays cannot penetrate lipiodol. When an extramedullar tumour is present, the lipiodol stops, gives a shadow on this part of the spine and thus we are able to control our clinical conclusions. 
PATHOLOGY OF SENSIBILITY

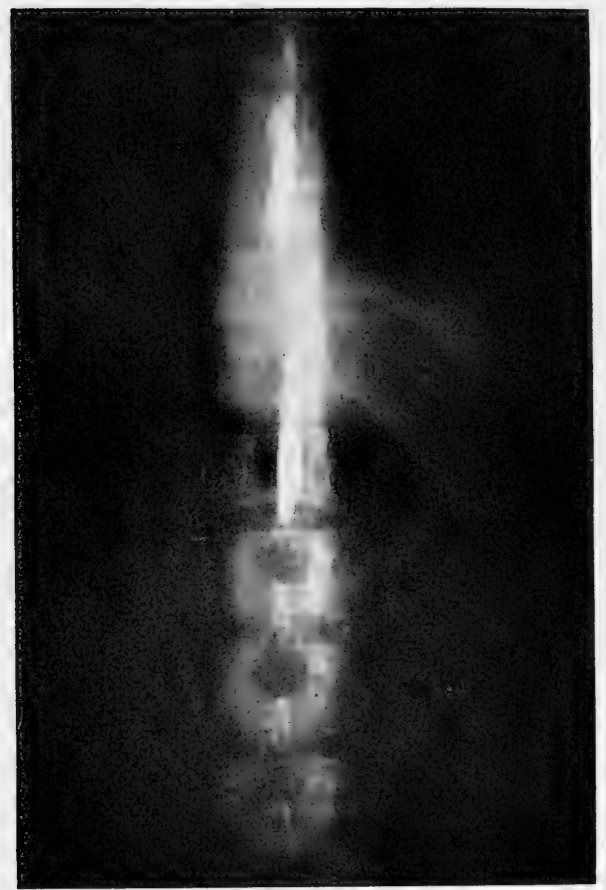

Fig. 8. Shadow of the Lipiodol after Suboccipital and after Lumbar INJECTION

The corpus of the 10th thoracal vertebra is free 

We have done much lipiodol-work in my clinic. In 1925 five tumours were successfully removed by operation by our surgeon Prof. O. Lanz after the clinical examination had been verified by lipiodol tests. In one of these cases the clinical diagnosis pointed to a tumour of the cauda equina. The lipiodol, however, stopped at the tenth thoracal segment. This was too high of course and we did not understand the difference between the results of our neurological examination and of the lipiodol test. At the operation two tumours were found, one above the other. The former was determined by the lipiodol test, the latter by our clinical examination.

Since using Sicard's method the spine has never been opened in my service without finding a tumour. It is also a great advantage that we are thus able to determine the lower border of the tumour. Lipiodol is injected after lumbar punction and then the patient is placed head-downwards. In figure 8 one may see the shadows of the lipiodol brought in after suboccipital and after lumbar puncture. The corpus of the tenth thoracal vertebra is free. This was the case of a girl, 18 years old, with the symptoms of a tumour on the spinal cord. Only a relatively small opening was made by the surgeon and a little tumour (endothelioma psammosum) could be removed. The patient, who before the operation was totally paralysed in both legs, improved quickly and was finally cured. It seems to me of great value for the surgeon to know not only the upper but also the lower border of the tumour, which has to be explored. The latter border may also be determined by lipiodol "ascendant," which is lighter than the spinal fluid.

In this lecture I have given you a short review of the organisation of sensibility in the nervous system and, further, the results of some of my investigations concerning the development of the pathways for various forms of sensation in the scale of evolution. Based on these studies I formed a 
biological conception of the organisation of sensibility in the central nervous system. Once more I must emphasise the fact that conduction of sensory impulses is not limited to the sensory nervous system. In my opinion the autonomic nervous system must play a significant rôle in conducting sensory stimuli, not only from the intestines, but also from the surface of the body. To study only the centrifugal functions of the autonomic system appears to me to be dogmatical and one of my reasons for giving this lecture was to lay greater stress on this side of the autonomic functions.

The other purpose of this lecture was of a totally different character. I have given you some of our results in tumours of the spinal cord, diagnosed with the help of the lipiodoltest. It is sometimes said that this method has dangers but I have not seen them. Only a slight rise of temperature and some pain at the upper border of the anaesthetic area, caused by the lipiodol lying on the roots, is stated, but these symptoms soon disappear. Still there was one disagreable factor in the use of this method. A good deal of my research work lies in the field of the physiological anatomy of the central nervous system. I studied with great interest the fine histological organisation of the brain and the spinal cord and the numerous pathways along which stimuli are spread through the nervous system. As clinician I used this hardly acquired knowledge to localise tumours and to obtain the therapeutical results. And now a new method in science suddenly springs up, which seems to make a good deal of this knowledge superfluous. Localising tumours in the spinal cord was thus far an artistic work, but now it is more simple. Just as when Dandy brought his famous air work in literature, two different lines of research and of thought clashed here.

It will be clear, however, that both these methods cannot be used separately but must be combined. Clinical examination, based on an exact knowledge of the structure and function of the nervous system, must be followed by 
these newer neurosurgical methods. The love for a special line of study may not hinder our search for the best therapeutic results.

\section{BIBLIOGRAPHY : LECTURE II}

Brouwer, B.: Die biologische Bedeutung der Dermatomerie. Folia neuro-biologica, 1915.

BROUWER, B.: Het autonome zenuwstelsel en het gevoel. Inaugurale Rede, Amsterdam, 1923.

BrotWer, B., AND OLJENICK, T.: Lipiodol-test in tumours of the spinal cord. Acta Psychiatrica-Neurologica, 1925.

Fabritides, H.: Zur Frage nach der sensibelen Leitung im menschlichen Rückenmark. Monatschrift für Psychiatrie und Neurologie., Band $31,1912$.

Head, H., and Sherren, T.: The consequences of injury to the peripheral nerves in man. Brain, 1905.

Head, H., and Holmes, G.: Sensory disturbances from cerebral lesions. Brain, Vol. XXXIV, 1911.

Petrèn, K.: Ưber die Bahnen der Sensibilität im Rückenmarke, besonders nach den Fällen von Stichverletzung studiert. Archiv für Psychiatrie, Band 47.

Petrèn, K.: Zur Frage vom Verlaufe der sensorischen Bahnen im Rückenmark. Neurologisches Centralblatt, 1916.

Ranson, S. W.: Unmyelinated nerve fibres as conductors of protopathic sensation. Brain, 1915, Vol. XXXVIII.

Ranson, S. W.: Non-medullated nerve fibres in the spinal nerves. The American Journal of Anatomy, Vol. 12, 1911.

Schoondermark, A.: Over gevoelsstoornissen, bÿ een antal klinische gevallen van periphere zenuwlaesies. Inaugural Dissertation, Amsterdam, 1920.

Sherrington, C. S.: Experiments in examination of the peripheral distribution of the fibres of the posterior roots of some spinal nerves. Philosophical Transactions of the Royal Society, London, 1893, Vol. 184, and 1898, Vol. 190.

Sicard et Forestier: Explanation radiologique par l'huile jodée. $L a$ presse médicale, 1923.

Thompson, T.: A case of subacute combined degeneration of the spinal cord demonstrating the nature of the afferent impulses in the posterior columns. Brain, Vol. XXXIV, 1911.

Winkler, C., AND van Rijnberk, G.: On function and structure of the trunkdermatoma I and II. Transactions of the Royal Academy for Sciences, 1902.

ZeenandelaAr, J.: Ontogenese en Phylogenese der Achterstrengkernen in verband met de sensibiliteit. Inaugural dissertation, Amsterdam, 1920. 


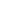




\section{THE SIGNIFICANCE OF PHYLOGENETIC STUDIES FOR THE NEUROLOGIST \\ THIRD HERTER LECTURE}




FOR THE NEUROLOGIST

For nine years I had the privilege of studying pathological anatomy of the nervous system at the Central Institute for Brainresearch, Amsterdam, conducted by Dr. C. U. Ariëns Kappers. The phylogenetic development of the nervous system, studied there, deeply impressed me. As clinician and pathologist I worked out some subjects in this line of science. In my opinion an exact knowledge of the relations in lower animals is valuable for the morphology, physiology and pathology of the human nervous system. Ontogenetic studies are of course no less important, but our knowledge in this line is far from complete.

To give you an impression of the significance of the phylogenetic line of thought I desire to tell you something about my research work in this matter. Yesterday, in treating the pathology of sensibility, I gave some examples relating to physiological anatomy. Today I shall discuss morphology, pathological anatomy and clinical neurology. I begin with the cerebellum.

In the older literature the human cerebellum was divided into a middle part, called the vermis with the flocculus and two lateral parts known as the hemispheres. Elliot Smith, Bradley and particularly Bolk divided the cerebellum differently. In studying several classes of mammals they preferred a transverse division, while the former was sagittal. The figure 9 shows the scheme of the cerebellum after Bolk. There is an anterior part, called the lobus anterior and a posterior part, called the lobus posterior. These are separated from one another by a deep fissure, the sulcus primarius. In the lobus anterior no division can be made into middle and lateral parts. The lobus posterior is sub- 
divided in several sublobi. Immediately behind the lobus anterior the lobus simplex is found. A subdivision into a middle and two lateral parts would also in this lobus be artificial. But in the rest of the lobus posterior such a distinction can be made. Bolk speaks of the lobus medianus posterior, and the lateral parts. The latter are chiefly composed of the lobi ansiformes. He mentions further a lobus paramedianus and a formatio vermicularis at both sides.

This work of Bolk has had a great influence on the development of the investigation of the structure and function of the

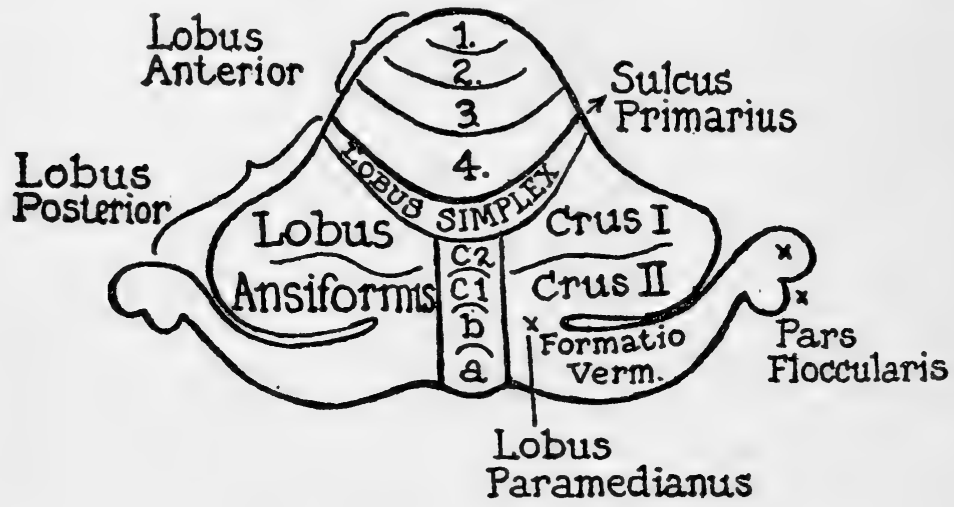

Fig. 9. Scheme of the Cerebellum

(After Bolk)

cerebellum, especially because he brought the principle of localisation in the cerebellum to the foreground. This is not a localization in a functional, but in a topographical sense. There is only one function in the cerebellum, but the various parts of the body must have a special localization in the cortex of the cerebellum.

van Rijnberk, Rothmann, Thomas and Durupt and others have done much experimental work in that line and advanced arguments in favour of Bolk's views.

After the above mentioned publications Edinger, how- 
ever, brought again the sagittal division to the foreground. $\mathrm{He}$ distinguished the palaeocerebellum, which is composed of the vermis, the flocculus and the paraflocculus, from the neocerebellum, consisting of the hemispheres. He did not confine himself to the mammal group, but studied all classes of vertebrates. In fishes, amphibians, reptiles and in birds the palaeocerebellum, the older part, is only found. In the lowest group of mammals the neocerebellum appears. There it is very small but grows bigger in higher mammals, being largest in man.

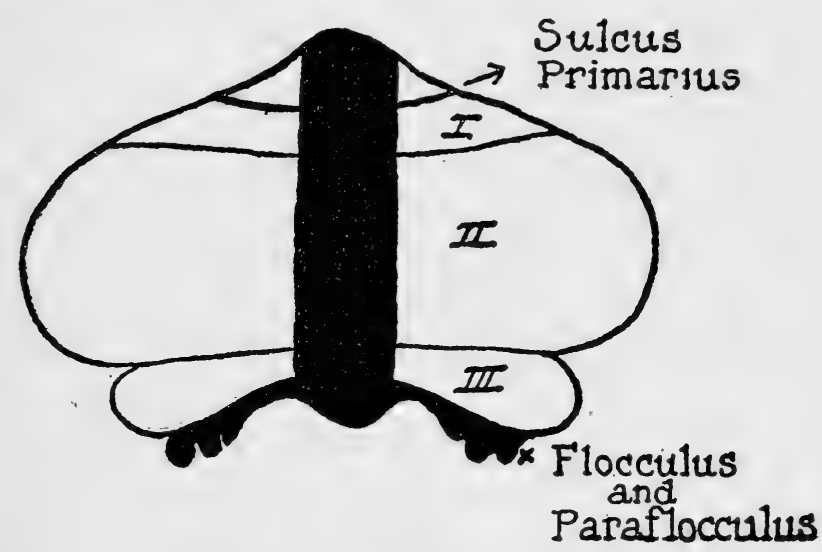

Fig. 10. Scheme of the Cerebellum

Black $=$ palaeocerebellum. White $=$ neocerebellum. (After Edinger)

Such were the different views held, when I got the opportunity of forming a personal opinion regarding this problem. I saw the brain of a man who during life had never shown any cerebellar symptom, but whose cerebellum on the left side was atrophied. The brainstem and the cerebellum were examined in a complete series of sections, stained after Weigert-Pal, van Gieson and with carmine. It was found that the atrophy of the cortex cerebelli was limited to the neocerebellum of Edinger, the vermis, flocculus and paraflocculus remaining normal. Afterwards I saw other brains 
of this type. They belong to the group of neocerebellar atrophies of $\mathrm{H}$. Vogt.

About the same time the ontogenetic studies of van Valkenburg showed, that the growth and the ripening of the cortex cerebelli in the human foetus differs in the neocere-

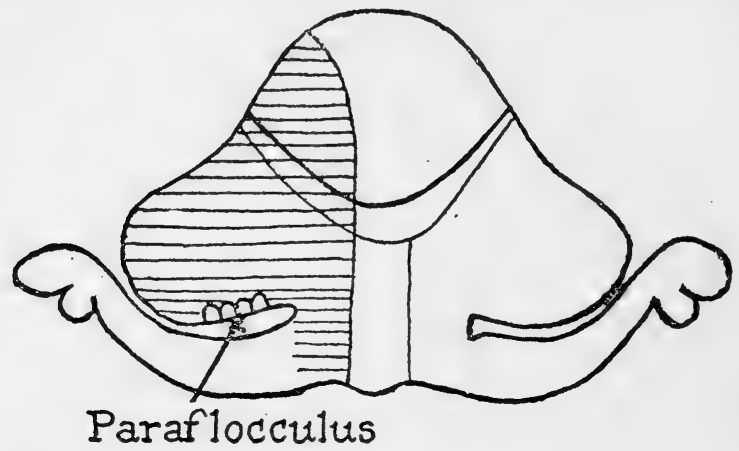

Fig. 11. Case I of Neocerebellar Atrophy

Extension of the atrophied area, drawn in the scheme of Bolk. Striped $=$ atrophied.

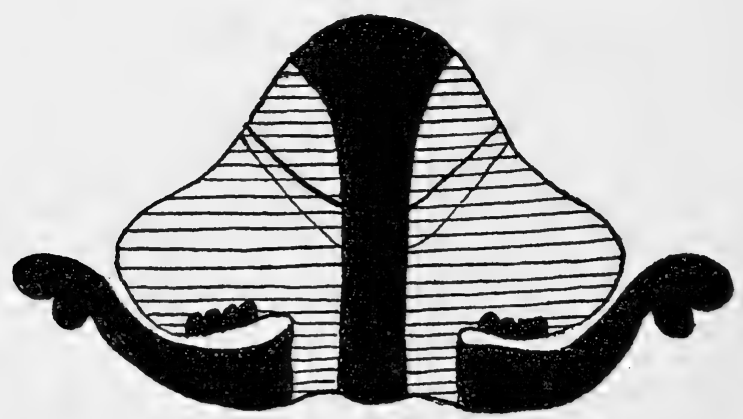

Fig. 12. Ripening of the Cortex Cerebelli

Black $=$ palaeocerebellum. Striped $=$ neocerebellum. (After van Valkenburg, drawn in the scheme of Bolk.)

bellum and in the palaeocerebellum. The various layers of the cortex begin to ripen in the palaeocerebellum, the neocerebellar part comes later. This is also the case with the myelinisation of the human foetus. Figure 10 shows the 
scheme of Edinger, figure 11 the results of the investigation of my first case of neocerebellar atrophy. In figure 12 I have drawn the results of the ontogenetic studies of van Valkenburg. The latters results and mine, as you will notice in the various figures, agree with those of Edinger. In this way the older division of a vermis and two hemispheres returned again. The sharp borders between the atrophied parts and normal parts of the cerebellar cortex in these cases of neocerebellar atrophy could not be fortuitous. The idea rose that these areas were changed, because these belonged to the younger parts of the cerebellum. You can thus understand that the conception of a palaeo- and a neocerebellum appealed to me.

Recently Marburg and Winkler advanced arguments against this conception of Edinger. One of my pupils, Dr. Koster, who studied two cases of neocerebellar hypoplasia in my laboratory, has given fuller data about the different opinions in this matter. I refer you to his book.

The brains of cases of neocerebellar atrophy I used to increase our knowledge of other parts of the central nervous system, connected with the cerebellum. I shall select as an example the system of the inferior olives, an extensive but mysterious formation in the medulla oblongata.

The inferior olives consist of large groups of cells, which send their fibres to the cortex cerebelli by the so-called tractus olivo-cerebellaris, which chiefly proceeds to the crossed side. These inferior olives degenerate when the cortex of the cerebellum is destroyed. Now I found in two cases of pure neocerebellar atrophy, that the degeneration did not extend over the whole inferior olives. The system of the inferior olives in man is composed of a principal olive, very large here, and of two accessory olives, a dorsal and a medio-ventral one. In these above mentioned cases of neocerebellar atrophy the accessory olives were spared, together with the oral part of the principal olive. The distribution of the degeneration is drawn in figure 13. 
These findings gave me the idea, that both these accessory olives must send their fibres to the palaeocerebellum and by far the greatest part of the principal olive to the neocerebellum. Hence it was necessary to divide the inferior olives into an older (palaeo-) and a newer (neo-) part. I was fortified in this idea, through studying brains of monkeys, dogs, cats and rabbits, where the principal olive is relatively small and the accessory olives comparatively

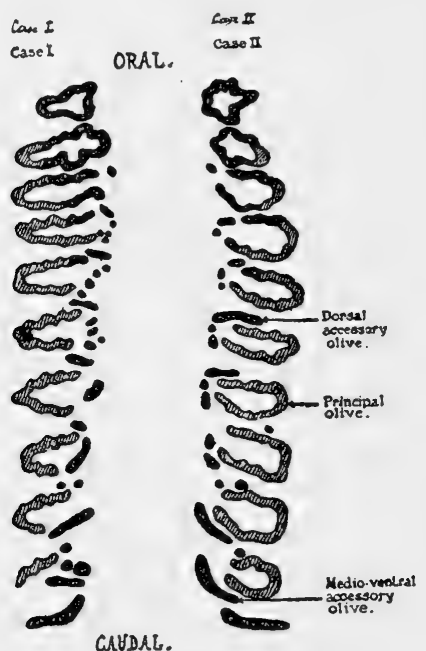

Fig. 13. Degeneration of the Inferior Olives in Two Cases of NEOCEREBELLAR ATROPHY

Striped $=$ degenerated $=$ neocerebellar. Black $=$ normal $=$ palaeocerebellar.

large. Besides, in studying the human foetus I found that these accessory olives are connected with the cerebellum by a special bundle, which I called the tractus parolivocerebellaris. This bundle is medullated much earlier than the rest of the tractus olivo-cerebellaris.

Careful investigations in comparative anatomy by Kooy and by Brunner have shown, that the medio-ventral accessory olive is the oldest part of the olive system, that 
then the dorsal olives develop and later on the principal olive. In the Central Institute for Brainresearch Kooy studied a great many series of sections of all classes of vertebrates. From his studies it is plain, that the accessory olives are relatively large in lower mammals, while the principal olive gradually grows bigger in the ascending scale in a oral-caudal direction. A comparison of Kooy's results and mine, obtained by the study of cases of neocerebellar atrophy, show that they agree in a large measure.

At the present stage of science we do not know much about the physiological significance of the inferior olives. Experimental destruction of these formations has not given clear results. Recent experiences in pathology of Marinesco, Gans and others point to their having something to do with motility. In a case, showing during life curious involuntary contractions in several groups of muscles (myoclonic contractions) Dr. Gans and I saw an extensive atrophy of the inferior olives, chiefly in the principal olive at both sides. There were, however, also some small congenital malformations in the cerebellum. Professor Precechtel of Prague studied this brain in my laboratory and will shortly publish the results. When taken in connection with other observations it may be expected, that the system of the inferior olives will play a rôle in diseases of the extrapyramidal systems. The physiological significance of the neocerebellum certainly differs from that of the palaeocerebellum. Hence we may be sure that the physiological significance of the older part of the inferior olives differ from that of the younger.

From these observations you may get the impression, that the combination of pathological anatomy and comparative anatomy benefit both branches of science.

Not unfrequently pathological processes prefer the younger parts of the central nervous system as Edinger, $\mathrm{H}$. Vogt, Jelgersma and others hold. It cannot be expected that the rule, that the younger parts of the nervous system 
resist noxious agents less, is always clear in pathology. For several causes usually coöperate in pathological conditions, namely heredity, the affinity of noxious agents to

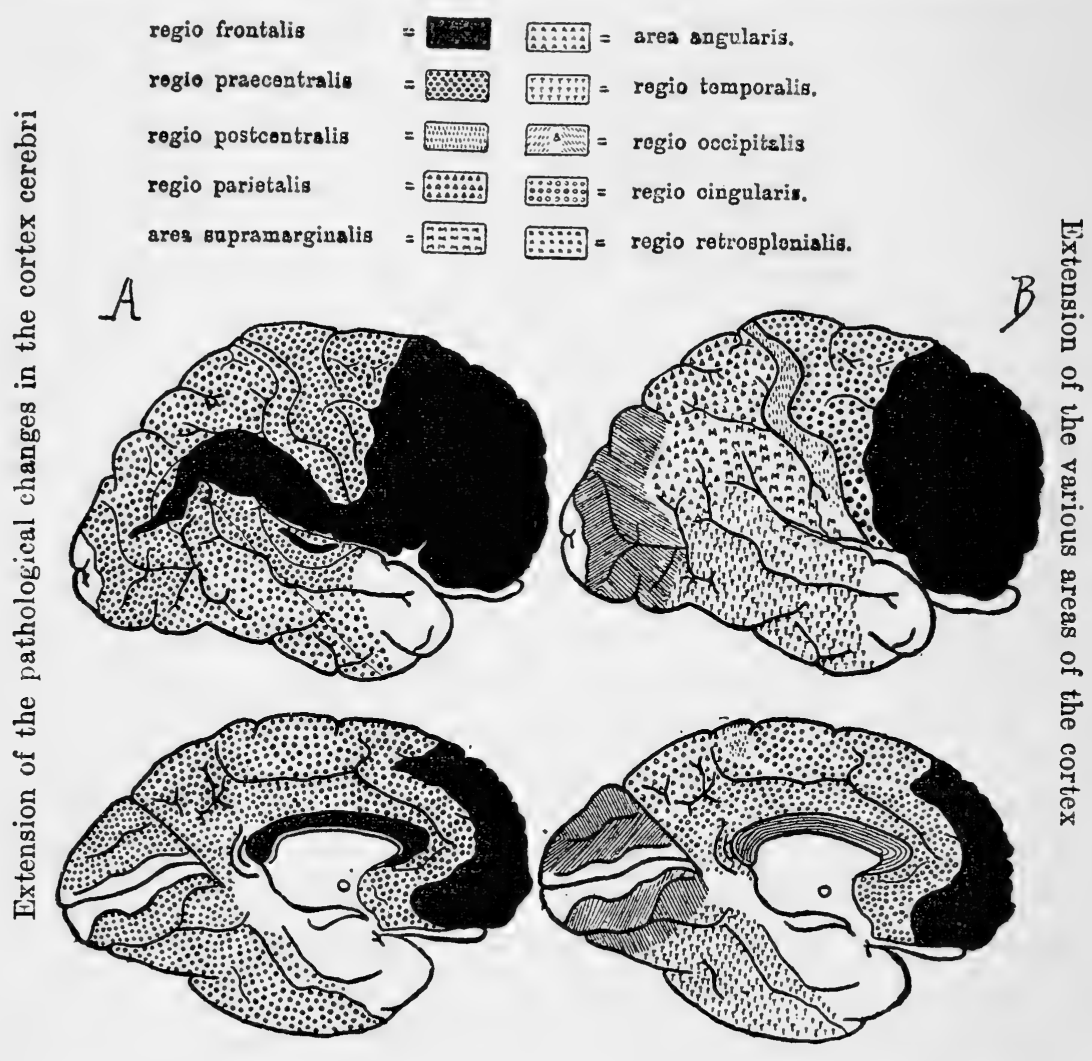

Frg. 14. $A$, Extension of the Pathological Changes in the Cortex Cerebri $B$, Areas of the Cortex Cerebri (After Brodmann)

Regio Hippocampi, Area Striata and Uncus Are White. changed.

special parts of the nervous system, conditions of the bloodvessels etc. But it is certain, that, when a pathologist is acquainted with the relations in comparative anatomy, he sees such analogies more frequently than others do. 
A good example of this is the brain of a man, who contracted in his third year an encephalitis, causing a leftside hemiplegia and an epilepsia. This man died at the age of 49 . At the post-mortem examination the right side of the telencephalon was much smaller than the left and there was microgyria of the cortex. Studying this brain in a complete series I found that the forebrain was largely destroyed, but that the boundaries of this lesion were not fortuitous.

The brain could be divided into three parts. In the first the alteration was very intensive, in the second less so, while in the third it was normal. The different areas may be seen in figure 14. The frontal area was very intensively damaged, while the sensu-motoric area in contrast showed much less changes. The ventral part of the parietal lobus, called the regio supramarginalis and angularis, was also very intensively changed.

In the occipital lobe a difference was very clear. The primary optic field in the cortex was spared, the lateral surface of the occipital lobe however (field 18 and 19 of Brodmann) showed alterations. A comparison of these drawings with the figure 15, in which a sketch is made of the development of the various areas in the ascending scale after the investigations of Brodmann, shows that the phylogenetically younger parts of the cortex are in my case intensively changed. It is often thought, that such extensive areas of destruction correspond with territories, which are supplied by blood-vessels, but in my experience this is frequently not so.

It cannot be fortuitous, that the frontal brain, the part of the pallium, that undergoes the greatest changes in the phylogenetic development suffers so frequently from various pathological processes. When, in the case here described, we at present pass by the most ventral part, the lesion stopped just at the sensu-motoric field, the area frontalis being intensively damaged. Descending in the scale of mammals this area frontalis gradually gets smaller. 
In rabbits it is insignificant and in lower animals like the hedge-hog, it cannot be recognised as such.

In the parietal field the conditions are similar. The ventral part, the regio supramarginalis and the regio angu-
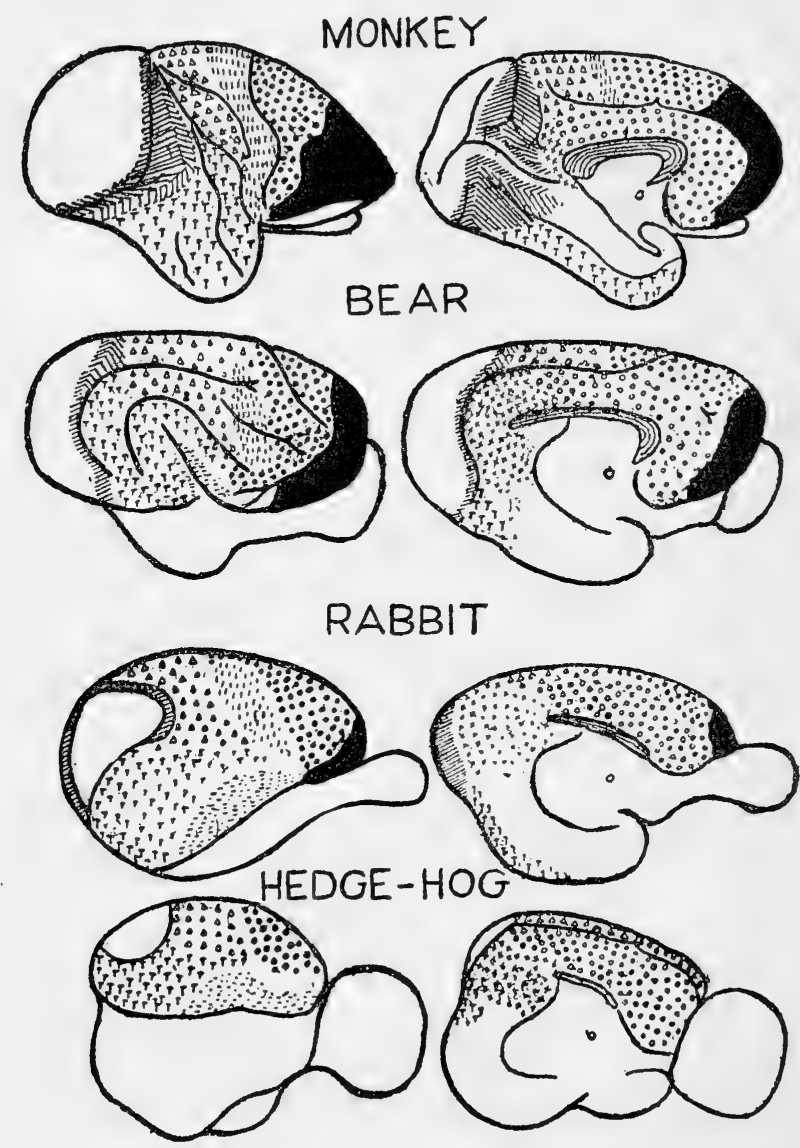

Fig. 15. Extension of the Cortical Areas in Mammals

See figure 14 for the names of the various areas. (After Brodmann)

laris, is much more changed than the remaining portion of the parietal lobe. Both these latter fields are only in the case of man clearly distinguishable as special fields. 
I shall now refer to the occipital lobe. As before described, the regio calcarina was better spared than the other parts of the occipital lobe. Now we see in figure 15 that the regio calcarina or area striata in the descending scale of mammals gradually predominates over the other optic fields. It is already clear in monkeys and in rabbits almost the whole optic field is occupied by the area striata, while in the hedge-hog nothing else is found than this primary optic field.

The regio hippocampi with the cornu ammonis were practically normal in our sections. They belong to the older parts of the cortex cerebri. Descending in the scale of mammals these parts gradually dominate over the other fields. It may be seen, that this so-called archipallium in the rabbit is much larger and that in the hedge-hog it is even the biggest field of the cortex. The same holds true in the regio retrosplenialis and in the frontal portion of the temporal lobe (the uncus) which are older in development and in my case are practically normal.

As I described above the lesion in the frontal area stopped just at the sensu-motoric field. This is not true, however, regarding the most ventral part of this latter area, as you may see in my figure 14 . We know from recent investigations that it is just this part of the sensu-motoric area that is developing later.

Ontogenetic and phylogenetic development run along parallel lines. In this respect it is interesting to notice that Gans found in several cases of atrophy of the cortex in older men, that the parts of the pallium, that had been latest in myelinisation, suffered most. This is in keeping with the above reasoning.

We shall now follow the same line of thought in a clinical subject. In a slightly different way Hughlings Jackson did this already in the case of more general clinical problems and in later time he was followed in this by Head, Mott, v. Monakow and others. 
Some years ago I published biological reflections on disseminated sclerosis. Further observations have not altered these ideas. Hence I shall repeat them, especially as some workers have misunderstood my point of view.

Sclerosis multiplex is, as you are aware, a chronic infectious disease of the central nervous system. The noxious agent, which as yet is not known, must be conducted chiefly along the bloodvessels to the central nervous system. This is proved by the fact, that the smaller sclerotic spots correspond in extent with the territories of the bloodvessels. This is not so clear in the bigger plaques because several of them have flown together.

These sclerotic areas are very irregularly distributed throughout the brain and the spinal cord. I remind you, that in this disease the myeline is far more seriously damaged than the cells and the axis cylinders. Hence the lesion of the central nervous system always seems to be worse than it really is. Impulses can be conducted through these foci, but not so well as under normal conditions.

Clinicians, accustomed to check their clinical findings by anatomical researches, know how dangerous it is to prophesy the extension and the localisation of the sclerotic foci from the clinical symptoms. Several authors expected, in cases with severe dysarthry, to see extensive damage in the medulla oblongata but did not find this. The contrary also occurs; one often sees many parts of the central nervous system strewn with sclerotic foci, while during life there were no clinical symptoms, indicating so serious alterations. Usually the anatomical section shows more than might have been expected at the clinical examination. So Oppenheim mentions, that in all the cases, anatomically controlled, he found plaques in the spinal trigeminal root, while no disturbances of sensibility in the face were found.

It is striking, that in this disease, where the central nervous system is so irregularly strewn with foci, there is yet some regularity in the clinical image. Sclerosis multiplex 
is rich in forms and in variations, still it cannot be denied, that a certain group of symptoms dominates in the clinical picture. These are especially spastic paresis of the legs with increased reflexes and the Babinski's sign, disturbances in coördination (tremor, ataxia), horizontal nystagmus, slight dysarthry, the disappearance of the abdominal reflexes.

When some of these principal symptoms are missing, it is hardly possible to diagnose sclerosis multiplex. Sensory disturbances, abnormalities in the movements of the eyemuscles, bladder and rectal functions remain in the background. They are very common in this disease, it is true, but are less intensive and have a tendency to pass away.

Several authors have tried to explain this contrast between the clinical picture and the anatomical substratum, but no satisfactory solution has yet been reached. So it has been said that spastic pareses are so frequent, because the pyramidal tracts are longer than the other tracts and hence have a greater chance of being attacked by foci. Another says that the disturbances in the sensibility seldom last, since the sensory fibres are more resistant than the motor ones. E. Müller explained this fact by arguing, that more ways are open for the conduction of sensory stimuli than for motor stimuli. Still other authors believe, that it is not possible to explain the chief symptoms of sclerosis multiplex by circumscript, well-localised alterations of the central nervous system. Hence they only speak of the "general symptoms" of this illness.

It is strange that no one has ever tried to consider all the symptoms from one point of view. This is possible, in my opinion, provided one places oneself at the point of view of evolution. We must take for granted that the older parts of the central nervous system, where the primitive functions are regulated, resist noxious agents better than the younger ones, where the higher functions are localised. I shall give some examples from my own experience. 
A female patient with sclerosis multiplex never showed disturbances in the motility of the cranial nerves, except a slight paresis of the left facial nerve. Speech was, however, almost impossible. The microscopic examination showed that the brainstem was richly provided with sclerotic areas, not only in the nuclei of the cranial nerves, but also in their roots (fig. 16). It is not strange, one may say, that the cranial nerves did not show clinically more paresis, since the axis cylinders are spared in the sclerotic areas, so that the stimuli can pass. That is so, but why could not the patient speak?

A second example is the following. It is a regular and early symptom of disseminated sclerosis, that the abdominalreflexes disappear. In sixty cases of our clinic fifty-four showed changes of the abdominal reflexes. Does the fact, that this reflex is partly connected with the forebrain and that the communicating fibres are interrupted, explain this? The arc of the knee reflex also communicates with the forebrain. Why then does this latter reflex not disappear with the same regularity as the abdominal reflex, seeing that sclerotic areas are so often present in the lumbar part of the spinal cord?

Nystagmus is a third example. This is a very frequent symptom in sclerosis multiplex; it was present in 37 of 60 cases in our clinic. Anatomical research can usually explain the existence of such a nystagmus, because there are many foci in the medulla oblongata. But why is this nystagmus so often exclusively horizontal? And why do these sclerotic areas so seldom cause a lasting palsy of the sixth or seventh nerves, although anatomically there are so many opportunities for this occurring?

In this connection I further call your attention to the frequent appearance of spastic paresis in the legs, which in this disease often shows some peculiarity. This paresis is often accompanied by a slight disturbance of the coördination. This does not occur in other cases of spastic paresis. 


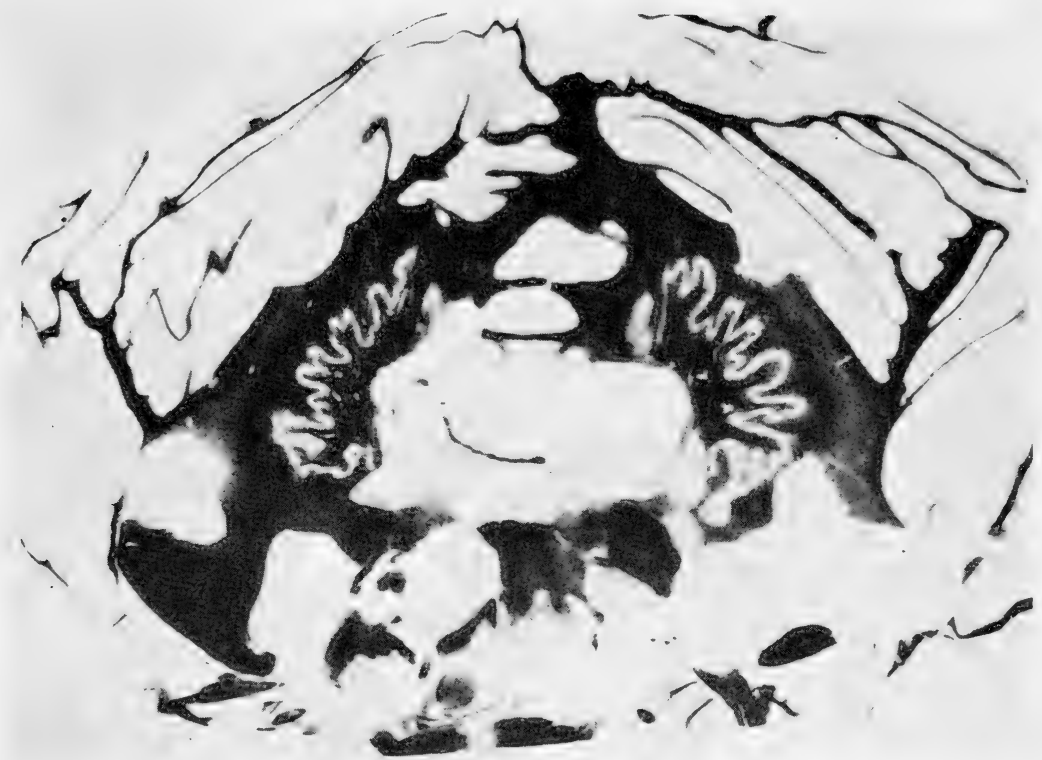

FIG. 16

The brain stem is filled up with sclerotic foci. There was a slight paresis of the left facial nerve, but no other disturbances in the motility of the head nerves. Speech, however, was almost totally impossible. 

Accurate investigation shows so often, that there is a slight tremor and a disturbance of the equilibrium along with some disorder in the coördination of the muscles of the trunk and of the extremities. The symptom of the spastic paresis in sclerosis multiplex is caused by a lesion of the pyramidal tracts, the accompanying symptoms of disorder of the coördination must be due to an injury of the cerebrocerebellar pathways. Why do these tracts so often suffer in sclerosis multiplex?

I shall now pass over other difficulties, only adding the interesting fact, that the same clinical image may also be found in cases, where the medulla oblongata and the medulla spinalis do not show sclerotic foci, but where the cerebral hemispheres only are affected.

Looking from the point of evolution it is easily understood, that the tracts which conduct the stimuli for speech are severely damaged in their function, while those for the more simpler movements of the cranial nerves remain normal. The former are the socalled phonetic tracts which are organized very late in phylogenesis and ontogenesis.

The same holds with regard to the abdominal reflexes. The term "reflex" is usually employed for mechanisms of a lower order. There are, however, several reflex movements, which are the expression of a higher organisation and which appear very late in the phylogenetic and ontogenetic development. To these belongs the abdominal reflex, which is only present in primates, while the knee reflexes, on the other hand, are found in several lower mammals. The abdominal reflexes appear late in ontogenesis (Cattaneo, Bychowski), they are not found until some months after birth, while the knee reflex is always present in newborn children.

In this way we can also understand why horizontal nystagmus is so often found in sclerosis multiplex, while other forms of nystagmus are rare. This symptom is usually caused by the foci in the region of the Deiters' nucleus and of the pos- 
terior longitudinal fasciculus. We must consider that the sidewards movement of both eyes alike in the horizontal level, is a function, only present in higher mammals, where the eyes are placed more frontal in the head and where the structure of the face makes it possible that such a function has acquired a great significance. In this connection I may note that experiences in the Great War have shown, that it is hardly possible to use the horizontal nystagmus for topographic diagnosis, since this symptom appears without any regularity in so many different injuries of the brain.

Spastic paresis in disseminated sclerosis is caused by injury being done to the pyramidal tracts, as mentioned above. These are phylogenetically and ontogenetically young, especially the part for the legs and hence we can understand that this function suffers frequently and early. The spasmus is caused through the influence of the older, subcortical motor tracts predominating. The above mentioned disturbances of coördination, accompanying the paresis, are often found in cases, where the strength of the movements is still normal. Meijer published, some years ago, a valuable paper on this matter. He showed after accurately investigating a great clinical material, that a slight tremor, some disturbance of the equilibrium and a slight disorder in the right coöperation of the muscles of the trunk and extremities, are very frequent at early periods in this illness.

Several authors are inclined to ascribe these disturbances to the cerebellum being injured. This, in my opinion, is not justified. For, although recent researches have shown, that the cerebellum is more frequently affected than Charcot believed, yet this is too rare to explain such a frequent symptom as this disturbance of coördination. In my opinion these disturbances are caused by lesions of the pathways between the neopallium and the cerebellum. These cerebro-cerebellar tracts, passing through the pons Varoli, are very young and have a late myelinization, still 
later than the pyramidal tracts. The great number of foci, regularly found in these areas, makes it conceivable, that an injury to these young systems may disturb the function depending on these tracts.

We know that disturbances of sensibility in sclerosis multiplex are rarely intensive and persistent. In the views I have advocated we must expect that the sense of deep sensibility and of tactile discrimination are more frequently disturbed. In regard to deep sensibility this is correct as Finkelnburg has demonstrated and it is also proved by my own experience. In many cases of sclerosis multiplex I found that only the sense of deep sensation was damaged. The tactile discrimination of two points is in these cases still insufficiently examined. Research in this direction is difficult, since patients with disseminated sclerosis are very often slightly dement and therefore unsuitable for fine tests.

The fact that the higher and the latest acquired functions are by preference disturbed, is also liable to psychical alterations. Recent researches have shown, that the cortex of the forebrain is more often affected than was formerly thought. The histological alterations are not so striking since the gliafibres in the cortex are not so inclined to grow excessively as in the other parts of the central nervous system. Aithough these modifications in the cortex of the Telencephalon vary greatly in intensity and in localization, the psychical phenomena of these sufferers are rather monotonous. The typical mental picture of patients with disseminated sclerosis is a slight dementia. The radius of their sight of their interest is smaller. They manifest a childlike feeling of security and a defective control of their affective life. Although still more severe alterations of the psyche may occur, this is an exception. Very commonly the mental condition of these sufferers is reduced to that of a child, to the socalled "puérilisme mentale" of the French clinicians. 
In this third lecture I have tried to give you some impression regarding the significance of phylogenetic studies for the neurologist. I have done this by giving examples from normal anatomy, pathological-anatomy and from the clinic. It is clear that this line of thought is more valuable for neurologists than for other clinicians. If there is one part of the body of vertebrate animals, where the great line, going upwards in the direction of man, may be seen, it is in the nervous system. Still I believe that such thoughts are valuable as well for other clinicians and pathologists. It is possible that such statements may also satisfy the student of other organs of the body, provided he has passed through comparative anatomy.

$\mathrm{My}$ opinion is that in the end the difference in vulnerability is caused by a difference in the chemical and physical structure. I cannot believe that cells and fibres, which have been present and functioned so long before others have, can be chemically and physically the same. But at the present stage of science we do not know very much about the finer and the inner organization of these cells and fibres. Hence we must now resort to such propositions as given above.

\section{BIBLIOGRAPHY: LECTURE III}

BoLk, L.: Das Zerebellum der Säugetiere. Monographie 1906, Bohn, Haarlem.

Bradiey, O. C.: On the development and homology of the mammalian cerebellar fissures. Journal of Anatomy and Physiology, 37, 1903.

BrodmanN, K.: Vergleichende Lokalisationslehre der Grosshirnrinde. Leipzig, 1909.

Brouwer, B.: Anatomische Untersuchung über das Kleinhirn des Menschen. Psychiatrische en Neurologische Bladen, 1915.

Brouwer, B.: Over hemiplegia spastica infantilis. Handelingen van het XVI Nederlandsch Natuur en Geneeshunkig Congres, April, 1917.

Brouwer, B.: The significance of phylogenetic and ontogenetic studies for the Neuropathologist. The Journal of Nervous and Mental Diseases, Vol. 51, 1920.

Brunner, H.: Zur Kenntnis der unteren Olive bei den Säugetieren. Arbeiten aus dem Obersteinerschen Institut, 22, 1917. 
Bychowskr, Z.: Úber das Verhalten einiger Haut- und Sehnenreflexe bei Kindern im Laufe des ersten Lebensjahres. Deutsche Zeitschrift für Nervenheilkunde, Band 34, 1908.

Cattaneo, C.: Ueber einige Reflexe im ersten Kindesalter. Jahrbuch für Kinderheilkunde, 1902.

Edrnger, L.: Über die Einteilung des Cerebellums. Anatomische Anzeiger, 1909, Band, 35.

Smith, G. Elliot: The Morphology of the human cerebellum. Review of Neurology and Psychiatry, 1903.

Finkelnburg, R.: Zur Frühdiagnose der multiplen Sklerose (sensibler Armtyphus). Münchener Mediz. Wochenschrift, 1910.

Gans, A.: Beitrag zur Kenntnis des Aufbau des Nucleus dentatus aus zwei Teilen namentlich auf Grund von Untersuchungen mit der Eisenreaktion. Zeitschrift für die gesamte Neurologie und Psychiatrie, Bd. 93, 1924.

Gans, A.: Degeneratie der beide Olijven als anatomisch substraat bij myoclonie. Psychiatrische en Neurologische, Bladen, 1926.

HäNel, H., ANd Bielschowsky, M.: Olivo-zerebellare Atrophie unter dem Bilde des familiären Paramyoklonus. Journal für Psychologie und Neurologie, 21, 1915.

Jelgersma, G.: Drei Fälle von Zerebellar atrophie der Katze; nebst Bermerkungen über das zerebro-zerebellare Verbindungssystem. Journal für Psychologie und Neurologie, 23, 1917.

Kooy, F. H.: The inferior olive in vertebrates. Folia Neuro-biologica, 23, 1918.

Koster, S.: Twee gevallen van hypoplasia Ponto-neocerebellaris. Inaugural Dissertation, Amsterdam, 1925.

Marburg, O.: Anatomie des Kleinhirns, in Handbuch der Neurologie des Ohres, 1924, von Alexander und Marburg.

Meijer, M.: Die diagnostische Bedeutung des Zitterns bei der multiplen Sklerose. Monatschrift für Psychiatrie und Neurologie, Band 25, 1909.

MÜller, E.: Die multiple Sklerose des Gehirns und Rückenmarks. Monographie, Jena, 1904.

VAN Valkenburg, C. T.: Bijdrage tot de kennis eener localisatie in de menschelijke kleine hersenen. Nederl. Tijdschrift voor Geneeskunde, 1912.

Vogt UND AstwazATURow: Über angeborene Kleinhirnerkrankungen mit Beiträgen zur Entwickelungsgeschichte des Kleinhirns. Archiv. für Psychiatrie, Bd. 49.

WINKLER, C.: A case of olivo-pontine-cerebellar atrophy and our conceptions of Neo- and Palaio-cerebellum. Schweizer Archiv für Neurologie und Psychiatrie, Band 13, 1923. 



\section{INDEX}

Abdominal reflexes, 57, 58, 59

Accessory olives, 50, 51

Air injection, 40

Archipallium, 55

Area frontalis, 53, 55

Area striata, 55

Areas of the cortex cerebri, 52, 54

Ariëns Kappers, 8, 34, 45

Astereognosis, 31

Autonomic sensibility, 28, 40

Axenfeld, 3

Ayer, 38

Babinski's sign, 57

Behr, 16

Binocular vision, 10, 14, 16, 19

Bolk, 36, 37, 45, 46

Brachium anterius, 14

Bradley, 45

Brodmann, 53

Brunner, 50

Bychowski, 59

Cattaneo, 59

Cauda equina, 39

Central optic radiation, 4

Centripetal sympathetic fibres, 28

Cerebellum, 45, 46, 47, 48, 49, 60

Cerebro-cerebellar pathways, 59, 62

Charcot, 60

Chatelin, 3

Chiasma, 3, 8, 12, 13

Corpus geniculatum externum, 4, $5,6,9,10,11,14,15,16,18$, $19,20,21,22$

Corpus quadrigeminum anticum, $4,10,16,18$

Cortical optic centre, 4,5

Crossing of the optic nerves, 3, 4, 10,13

Cushing, 3
Dandy, 40

Deep sensibility, 27, 29, 37, 61

Dementia, 61

Dermatom, 36, 37, 38

Discrimination, 27, 30, 34, 61

Disseminated sclerosis, 56-61

Durupt, 46

Dysarthry, 57

Edinger, 32, 46, 47, 49

Elliot Smith, 45

Encephalitis, 53

Epicritic sensibility, 25, 26

External geniculate body: see Corpus geniculatum externum

Extrapyramidal systems, 51

Fabritius, 29

Finkelnburg, 61

Flocculus, 45, 47

Forestier, 38

Formatio vermicularis, 46

Gans, 51, 55

Gashell, 28

Gliafibres, 61

Gnostic sensibility, 30, 31, 35, 37

Gordon Holmes, 3, 22

Gyrus angularis, 14

Gyrus centralis posterior, 30

Head, 27, 28, 29, 55

Hemianopsia, 5, 6, 22

Henschen, 5, 6, 12, 21

Herrenheiser, 6

Herrick, 32

Horizontal meridian of the retina, 21

Huber, 28

Hughlings Jackson, 55

Hypophysis, 12 
Inferior olives, 49, 50, 51

Intervertebral ganglion, 29

Intestines, 28, 40

Jelgersma, 51

Kocher, 36

Kooy, 50, 51

Koster, 49

Langley, 28

Lanz, 39

Leriche, 28

Leueiscus rutilus, 7

Lipiodol ascendant, 39

Lipiodol descendant, 38, 39, 40

Lister, 3,6

Lobus ansiformis, 46

Lobus simplex, 46

Lophius bondegossa, 31

Lubsen, 7

Lutz, 16

Macula, 5, 6, 11, 12, 13, 18, 19, 21, 22

Marburg, 49

Marie (P.), 3

Marinesco, 51

Mesial fillet, 30, 33

Meÿer (A.), 3

Meÿer (M.), 60

Microgyria, 53

Minkowski, 10

von Monakow, 5, 6, 22, 55

Monocular vision, 15, 16, 17, 19

Mott, 55

Müller, 57

Myelinisation, 55, 60

Myoclonic contractions, 51

Neocerebellum, 47, 48, 49, 50

Neocerebellar atrophy, 48, 49, 50

Neosensibility, 33, 34

Newton, 3

Non-autonomic sensibility, 35,37

Nucleus of Burdach, 29, 31, 32

Nucleus of Deiters, 59

Nucleus of Goll, 29, 31, 32
Nucleus trigeminalis frontalis, 31 , $32,33,34$

Nystagmus, 57, 58, 59, 60

Ontogenetic development of sensibility, 34

Operation on the retina, $6,7,8,11$

Oppenheim, 56

Optic nerves, 3, 4, 6, 8, 12

Optic radiation, 6,21

Optic thalamus, 13, 30, 31

Optic tracts, 8, 9, 13, 18, 19

Overbasch, 9, 10, 11

Palaeocerebellum, 47, 48, 50

Palaeosensibility, 32, 33, 34

Paraflocculus, 47

Parasympathetic system, 28

Pathology of sensibility, 27, 61

Pernicious anaemia, 37

Petrèn, 29

Phonetic tracts, 59

Pick, 6

Pons Varoli, 60

Posterior columns, 29, 30, 31, 32, 34, 35,37

Posterior horn, 29, 31, 32, 34

Posterior longitudinal fasciculus, 59

Precechtel, 51

Principal olive, 49, 50

Proprioceptive sensibility, 27, 29

Protopathic sensibility, 27, 28, 29

Puerilisme mentale, 61

Pulvinar, 4, 13, 14

Putnam, 22

Ranson, 29

Regio angularis, 52, 54

Regio hippocampi, 55

Regio retrosplenialis, 55

Regio supramarginalis, 52, 54

Rhombus maximus, 31

Rivers, 27

Rönne, 21

Rothmann, 46

v. Rÿnberk, 38, 46 
Schoondermark, 27

Sclerosis multiplex: see Disseminated sclerosis

Sclerotic degenerations, 36

de Schweinitz, 3

Segmental anatomy, 36

Sherren, 27

Sherrington, 36, 38

Sicard, 38, 39

Spinal trigeminal root, $31,33,56$

Spine, 38, 39

Spino-thalamic tract, 30,33

Spirochaetosis, 37

Stereognosis, 30

Stereoscopic vision, 14

Suboccipital puncture, 38, 39

Sulcus primarius, 45

Tabes, 37

Tectum opticum, 7

Telencephalon, 53, 61
Third dimension, 22, 23

Thomas, 46

Tournay, 28

Tractus olivo-cerebellaris, 49, 50

Trigeminal nerve, 29, 31

Tumour, 5, 12, 13, 30, 36, 38, 39, 40

v. Valkenburg, 29, 49

Vagus, 28

Vital sensibility, $30,31,33,35,36$, 37

Vogt (H.), 48, 51

Wilbrand, 12

Winkler, 38, 49

X-ray examination, 38

Zeehandelaar, 34

Zeeman, 7, 16, 1923 



\section{Sans Tache}

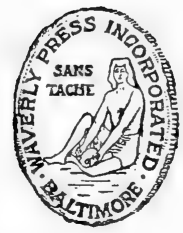




\section{Sans Tache}

T THE "elder days of art" each artist or craftsman enjoyed the privilege of independent creation. He carried through a process of manufacture from beginning to end. The scribe of the days before the printing press was such a craftsman. So was the printer in the days before the machine process. He stood or fell, as a craftsman, by the merit or demerit of his finished product.

Modern machine production has added much to the worker's productivity and to his material welfare; but it has deprived him of the old creative distinctiveness. His work is merged in the work of the team, and lost sight of as something representing him and his personality.

Many hands and minds contribute to the manufacture of a book, in this day of specialization. There are seven distinct major processes in the making of a book: The type must first be set; by the monotype method, there are two processes, the "keyboarding" of the MS and the casting of the type from the perforated paper rolls thus produced. Formulas and other intricate work must be hand-set; then the whole brought together ("composed") in its true order, made into pages and forms. The results must be checked by proof reading at each stage. Then comes the "makeready" and press-run and finally the binding into volumes.

All these processes, except that of binding into cloth or leather covers, are carried on under our roof.

The motto of the Wavery Press is Sans Tache. Our ideal is to manufacture books "without blemish"-worthy books, 
worthily printed, with worthy typography-books to which we shall be proud to attach our imprint, made by craftsmen who are willing to accept open responsibility for their work, and who are entitled to credit for creditable performance.

The printing craftsman of today is quite as much a craftsman as his predecessor. There is quite as much discrimination between poor work and good. We are of the opinion that the individuality of the worker should not be wholly lost. The members of our staff who have contributed their skill of hand and brain to this volume are:

Composing: Richard King, William Fite, Anthony Wagner, John Crabill, Herbert Leitch, Harry LaMotte, Charles Wyatt, James Jackson, William Sanders, Austin Uhland, Edward Rice, George Moss, Henry Shea, Theodore Nilson.

Caster: Kenneth Brown, Charles Aher, Ernest Wann, Mahlon Robinson, Martin Griffen, Charles Fick, George Bullinger, Frank Malanosky, Henry Lee, George Smith.

Keyboard: Harry Susemihl, Helen Twardowicz, Vera Taylor, Mildred Lambert.

Press: R. M. Gallagher, Hugh Gardner.

Folder: Laurence Krug, Shipley Dellinger.

Cutter: William Armiger.

Proof Room: Sarah Katzin, Mary Reed, Alice Reuter, Lucille Bull, Ethel Strasinger, Ruth Treischman, Dorothy Strasinger, Ida Zimmerman, George Southworth, Angeline Eifert, Audrey Tanner, Lillian Gilland. 


\section{From the List of Nere Publications}

\section{Anatomy of the Wood Rat}

$\$ 5.00$

\section{By A. Brazier Howeli}

The first comprehensive study of the common North American wood rat. Discusses internal anatomy. Comparative in treatment. Number one of the Monographs of the American Society of Mammalogists. Cloth. $6 \times 9$. 224 pages, fully illustrated in color and black and white. Bibliography.

\section{Local Immunization}

By A. Besredka, translated by Dr. HARry Plotz.

Presents a new and revolutionary view of immunity, a new method of vaccination, a new method of treatment, growing out of the author's researches at the Pasteur Institute. A book of importance to the whole medical profession. Cloth. $5 \times 8.216$ pages. Index. Bibliography.

\section{Significance of the Physical Constitution in Mental Disease}

By F. I. Wertheimer and F. E. Hesketh. Preface by L. F. Barker.

Traces the development of the conception of body types and their relation to mental function and mental disease, with an analysis of anthropometric methods as they relate to psychiatry. Cloth. $6 \times 9$. 76 pages, copiously illustrated. Bibliography. Index.

\section{Symbionticism and the Origin of Species}

By Ivan E. WALLIN

Tiny bodies, called mitochondria, found in the cells of all living things are themselves living organisms, says the author. Their presence may give rise to new tissue and organs. Therefore they may be the clue to unraveling the perplexing mystery of the origin of species, the author argues. You may not agree, but you will find the theory worthy of consideration. Cloth. $6 \times 9.171$ pages, illustrated. Bibliography. Index.

\section{THE WILLIAMS \& WILKINS COMPANY} Publishers of Scientific Books and Periodicals BALTIMORE, U.S.A. 





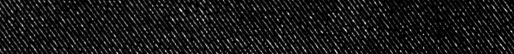

2.

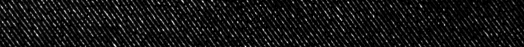
F. 2.

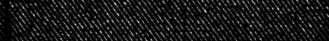

H.1.

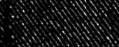

.

a.

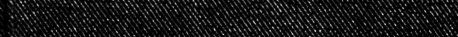

(1)

.1.

(1.

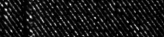

(1)

$\ldots$

. . . . . . . .

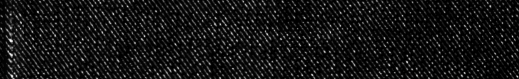

(1)

(1) . . . . .

(1)

. . . . . . . . . .

. . . . .

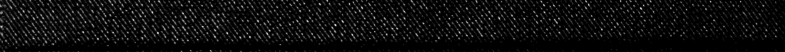

